ARTICLE

\title{
3D atomic-scale imaging of mixed Co-Fe spinel oxide nanoparticles during oxygen evolution reaction
}

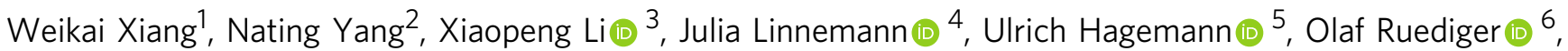 \\ Markus Heidelmann ${ }^{5}$, Tobias Falk ${ }^{7}$, Matteo Aramini ${ }^{8}$, Serena DeBeer (1) ${ }^{6}$, Martin Muhler (D) ${ }^{7}$, \\ Kristina Tschulik (i) ${ }^{4} \&$ Tong Li (iD) ${ }^{1 凶}$
}

The three-dimensional (3D) distribution of individual atoms on the surface of catalyst nanoparticles plays a vital role in their activity and stability. Optimising the performance of electrocatalysts requires atomic-scale information, but it is difficult to obtain. Here, we use atom probe tomography to elucidate the $3 \mathrm{D}$ structure of $10 \mathrm{~nm}$ sized $\mathrm{Co}_{2} \mathrm{FeO}_{4}$ and $\mathrm{CoFe}_{2} \mathrm{O}_{4}$ nanoparticles during oxygen evolution reaction (OER). We reveal nanoscale spinodal decomposition in pristine $\mathrm{CO}_{2} \mathrm{FeO}_{4}$. The interfaces of $\mathrm{Co}$-rich and Fe-rich nanodomains of $\mathrm{Co}_{2} \mathrm{FeO}_{4}$ become trapping sites for hydroxyl groups, contributing to a higher OER activity compared to that of $\mathrm{CoFe}_{2} \mathrm{O}_{4}$. However, the activity of $\mathrm{Co}_{2} \mathrm{FeO}_{4}$ drops considerably due to concurrent irreversible transformation towards $\mathrm{Co}^{\mathrm{IV}} \mathrm{O}_{2}$ and pronounced Fe dissolution. In contrast, there is negligible elemental redistribution for $\mathrm{CoFe}_{2} \mathrm{O}_{4}$ after OER, except for surface structural transformation towards $\left(\mathrm{Fe}^{\mathrm{III}}, \mathrm{Co}^{\mathrm{III}}\right)_{2} \mathrm{O}_{3}$. Overall, our study provides a unique 3D compositional distribution of mixed $\mathrm{Co}$-Fe spinel oxides, which gives atomic-scale insights into active sites and the deactivation of electrocatalysts during OER.

\footnotetext{
${ }^{1}$ Institute for Materials, Ruhr-Universität Bochum, Universitätsstraße 150, 44801 Bochum, Germany. ${ }^{2}$ CAS Key Laboratory of Low-Carbon Conversion Science and Engineering, Shanghai Advanced Research Institute (SARI), Chinese Academy of Sciences (CAS), 201210 Shanghai, China. ${ }^{3}$ State Key Laboratory for Modification of Chemical Fibers and Polymer Materials and College of Materials Science and Engineering, Donghua University, 201620 Shanghai, China. ${ }^{4}$ Faculty of Chemistry and Biochemistry, Analytical Chemistry II, Ruhr-Universität Bochum, Universitätsstraße 150, 44801 Bochum, Germany. ${ }^{5}$ Interdisciplinary Center for Analytics on the Nanoscale (ICAN) and Center for Nanointegration Duisburg-Essen (CENIDE), University of Duisburg-Essen, Carl-Benz-Straße 199, 47057 Duisburg, Germany. ${ }^{6}$ Max Planck Institute for Chemical Energy Conversion, Stiftstraße 34-36, 45470 Mülheim an der Ruhr, Germany. ${ }^{7}$ Faculty of Chemistry and Biochemistry, Laboratory of Industrial Chemistry, Ruhr-Universität Bochum, Universitätsstraße 150, 44801 Bochum, Germany. ${ }^{8}$ Diamond Light Source, Harwell Science and Innovation Campus, Chilton, Didcot OX11 ODE, UK. ${ }^{4}$ email: tong.li@rub.de
} 
ydrogen has long been proposed as a clean energy carrier within sustainable energy infrastructure. Although water electrolysis is a key technology in the production of hydrogen, it remains inefficient, and there are many complex challenges to improve its efficiency. One of the major hurdles is the limitation in the performance of anode electrocatalysts, where the oxygen evolution reaction (OER) takes place ${ }^{1,2}$. Optimisation of OER electrocatalysts requires a detailed understanding of the correlation between the surface composition of electrocatalysts and their activity and stability. However, it is notoriously challenging to perform a full three-dimensional (3D) structural and chemical characterisation of the topmost atomic layers of electrocatalysts, especially for catalyst nanoparticles $<100 \mathrm{~nm}$ in diameter. In addition, the electrocatalyst surfaces undergo drastic structural and compositional changes during OER. Therefore, to develop high-performance OER electrocatalysts, it is imperative to thoroughly evaluate the contribution made by individual atoms during reactions to the relationships between catalytic activity and stability.

Mixed 3d transition metal oxides, such as mixed Co-Fe spinel oxides, have attracted much attention in the context of OER electrocatalysts due to their high abundance, low cost and rich redox chemistry ${ }^{3-5}$; these characteristics make them attractive alternatives to the high-cost benchmark noble metal-based oxides, i.e., $\mathrm{IrO}_{2}$ and $\mathrm{RuO}_{2}$. Depending on the composition, two spinel structures can be formed: (i) spinel, whereby a divalent cation, e.g., $\mathrm{Co}^{\mathrm{II}}$, is located at the tetrahedral site, and trivalent $\mathrm{Fe}^{\mathrm{III}}$ at the octahedral site, and (ii) inverse spinel, whereby $\mathrm{Co}^{\mathrm{II}}$ is located at the octahedral site and $\mathrm{Fe}^{\mathrm{III}}$ at both the tetrahedral and octahedral sites 6 . The addition of small amounts of $\mathrm{Fe}$ in $\mathrm{Co}_{3} \mathrm{O}_{4}$ has been found to reduce the overpotential, while excess $\mathrm{Fe}$ increases the overpotential ${ }^{7,8}$. However, the role of Fe of mixed Co-Fe oxides or (oxy)hydroxides in catalysing OER is poorly understood, being the subject of ongoing and intense debate $4,5,9-14$. Additionally, although surface chemical and structural rearrangement of Co-based spinel oxides has been recently observed ${ }^{4,15-20}$, the surface reconstruction or phase transformation responsible for the change in OER activity and stability has not yet been studied in-depth. Therefore, this study aims to (i) correlate changes in OER performance with structural and compositional evolution of $\mathrm{Co}_{2} \mathrm{FeO}_{4}$ spinel and $\mathrm{CoFe}_{2} \mathrm{O}_{4}$ inverse spinel, thereby elucidating their deactivation processes during OER, and (ii) pinpoint the role of Fe in the OER activity of mixed Co-Fe oxides.

In this work, we use atom probe tomography (APT), in conjunction with X-ray photoelectron spectroscopy (XPS), X-ray absorption spectroscopy (XAS), high-resolution transmission electron microscopy (HRTEM) and electrochemical impedance spectroscopy (EIS) to characterise the evolution of the oxidation state, structure and composition on the surfaces of $\mathrm{Co}_{2} \mathrm{FeO}_{4}$ and $\mathrm{CoFe}_{2} \mathrm{O}_{4}$ nanoparticles during cyclic voltammetry (CV) measurements under OER conditions. Comprehensive information regarding the surface state changes is obtained by the scalebridging method, including oxidation state measurements of bulk volume and top surface layer $(5-10 \mathrm{~nm})$ of nanoparticles by XAS and XPS, respectively, along with nanoscale and atomic-scale elemental and structural characterisation of individual nanoparticles by APT and HRTEM. Our study reveals the presence of Co-rich and Fe-rich nanodomains, created by spinodal decomposition, in pristine $\mathrm{Co}_{2} \mathrm{FeO}_{4}$ and most likely in most mixed $\mathrm{Co}_{x} \mathrm{Fe}_{(3-x)} \mathrm{O}_{4}$ spinel oxides when $x$ is in the range of 1.1-2.7 due to the miscibility gap $^{21,22}$. Interestingly, hydroxyl groups were trapped at the interface between the nanodomains, possibly yielding a significantly enhanced OER activity of pristine $\mathrm{Co}_{2} \mathrm{FeO}_{4}$ compared to $\mathrm{CoFe}_{2} \mathrm{O}_{4}$. During OER, different levels of $\mathrm{Fe}$ dissolution occur in the nanodomains of $\mathrm{Co}_{2} \mathrm{FeO}_{4}$, along with concurrent irreversible structural transformation towards $\mathrm{Co}^{\mathrm{IV}} \mathrm{O}_{2}$, leading to a substantial decrease in the OER activity. In contrast, negligible $\mathrm{Fe}$ loss was observed for $\mathrm{CoFe}_{2} \mathrm{O}_{4}$. Instead, $\left(\mathrm{Fe}^{\mathrm{III}}, \mathrm{Co}^{\mathrm{III}}\right)_{2} \mathrm{O}_{3}$ was formed on the surface, further decreasing the OER activity of $\mathrm{CoFe}_{2} \mathrm{O}_{4}$. Overall, our 3D atomic-scale data, combined with X-ray- and electron-based microscopy and electrochemical data, show great promise for improving understanding of the complex structure-activity-stability relationships of electrocatalysts.

\section{Results}

Structure, size and morphology of spinel oxide nanoparticles. $\mathrm{Co}_{2} \mathrm{FeO}_{4}$ and $\mathrm{CoFe}_{2} \mathrm{O}_{4}$ nanoparticles were synthesised by a hydrothermal method (see Methods). Both pristine nanoparticles have the standard cubic spinel structure $\left(\mathrm{Fd} \overline{3} \mathrm{~m}^{23}\right)$, as confirmed by X-ray powder diffraction (XRD) (Supplementary Fig. 1). The size of pristine $\mathrm{Co}_{2} \mathrm{FeO}_{4}$ and $\mathrm{CoFe}_{2} \mathrm{O}_{4}$ nanoparticles is $10.3 \pm 2.6 \mathrm{~nm}$ and $10.4 \pm 2.7 \mathrm{~nm}$, respectively, and both have a spherical shape (Supplementary Figs. $2 \mathrm{a}-\mathrm{d}$ and $3 \mathrm{a}-\mathrm{d}$ ). The lattice constants of $\mathrm{Co}_{2} \mathrm{FeO}_{4}$ and $\mathrm{CoFe}_{2} \mathrm{O}_{4}$ nanoparticles, as measured from the selected area electron diffraction patterns shown in Supplementary Figs. 2e and $3 \mathrm{e}$, is $8.60 \AA$ and $8.69 \AA$, respectively. The difference in the lattice constants originates from the differences between $\mathrm{Co} / \mathrm{Fe}$ contents and their radius $\left(\mathrm{Co}^{3+}\right.$ has a radius of $0.61 \AA$, which is slightly less than the $\mathrm{Fe}^{3+}$ radius of $0.65 \AA^{24}$ ); this is consistent with the XRD data (in Supplementary Fig. 1), whereby the diffraction peaks of $\mathrm{Co}_{2} \mathrm{FeO}_{4}$ are shifted to higher $2 \theta$ values compared to those of $\mathrm{CoFe}_{2} \mathrm{O}_{4}$.

Electrochemical performance. The electrocatalytic activity was measured by linear sweep voltammetry (LSV), using a scan rate of $10 \mathrm{mV} / \mathrm{s}$ on a rotating disk electrode $(\mathrm{RDE})$, on $\mathrm{Co}_{2} \mathrm{FeO}_{4}$ and $\mathrm{CoFe}_{2} \mathrm{O}_{4}$ nanoparticles in the pristine state and after various $\mathrm{CV}$ cycles in $1.0 \mathrm{M} \mathrm{KOH}$ under OER conditions, Fig. 1a-d. Tafel slopes were derived from the LSV data, see Fig. 1e, f. The current density was normalised to surface areas determined by the Brunauer-Emmett-Teller (BET) method from $\mathrm{N}_{2}$ physisorption measurements (Supplementary Fig. 4, additionally, the current density normalised to the geometric surface area of glassy carbon electrodes was provided in Supplementary Fig. 5). Ohmic drop $\left(i R_{s}\right)$ correction ( $R_{s}$ extracted from Nyquist plots) was applied to compensate for a lowering of the actual potential resulting at the electrode as compared to the nominally applied one due to current flux in the highly resistive system ${ }^{5}$.

The LSV plots, shown in Fig. $1 \mathrm{a}, \mathrm{b}$, reveal that pristine $\mathrm{Co}_{2} \mathrm{FeO}_{4}$ exhibits a higher OER activity than pristine $\mathrm{CoFe}_{2} \mathrm{O}_{4}$, since the overpotential of $\mathrm{Co}_{2} \mathrm{FeO}_{4}\left(359 \mathrm{mV}\right.$ at $\left.10 \mu \mathrm{A} / \mathrm{cm}^{2}\right)$ is lower than that of $\mathrm{CoFe}_{2} \mathrm{O}_{4}\left(432 \mathrm{mV}\right.$ at $\left.10 \mu \mathrm{A} / \mathrm{cm}^{2}\right)$. Pristine $\mathrm{Co}_{2} \mathrm{FeO}_{4}$ has a Tafel slope of $43 \pm 1 \mathrm{mV} / \mathrm{dec}$ (Fig. 1e), while pristine $\mathrm{CoFe}_{2} \mathrm{O}_{4}$ has a much larger Tafel slope of $79 \pm 2 \mathrm{mV} / \mathrm{dec}$ (Fig. 1f), indicating that OER charge transfer kinetics are faster on pristine $\mathrm{Co}_{2} \mathrm{FeO}_{4}$ than on pristine $\mathrm{CoFe}_{2} \mathrm{O}_{4}$. The measured Tafel slope of pristine $\mathrm{Co}_{2} \mathrm{FeO}_{4}$ nanoparticles is also lower than most pristine $\mathrm{Co}_{3} \mathrm{O}_{4}$ and Co-based spinel oxide nanoparticles $(\sim 60 \mathrm{mV} / \mathrm{dec})^{19,25}$. Increasing the number of $\mathrm{CV}$ cycles leads to a gradual deterioration in activity of both $\mathrm{Co}_{2} \mathrm{FeO}_{4}$ and $\mathrm{CoFe}_{2} \mathrm{O}_{4}$ (Fig. 1a, b, e, f). In particular, the Tafel slope of $\mathrm{Co}_{2} \mathrm{FeO}_{4}$ increases to $83 \pm 2 \mathrm{mV} / \mathrm{dec}$ after 1000 cycles, which is almost double the Tafel slope of the pristine state, while the Tafel slope of $\mathrm{CoFe}_{2} \mathrm{O}_{4}$ increases slightly to $83 \pm 1 \mathrm{mV} / \mathrm{dec}$. Thus, despite the high OER activity of pristine $\mathrm{Co}_{2} \mathrm{FeO}_{4}$, its OER activity drops as the number of $\mathrm{CV}$ cycles increases, eventually reaching similar values as detected for the less active $\mathrm{CoFe}_{2} \mathrm{O}_{4}$.

Furthermore, $\mathrm{Co}_{2} \mathrm{FeO}_{4}$ exhibits pronounced redox couples during CV measurements (inset of Fig. 1c). Specifically, during 

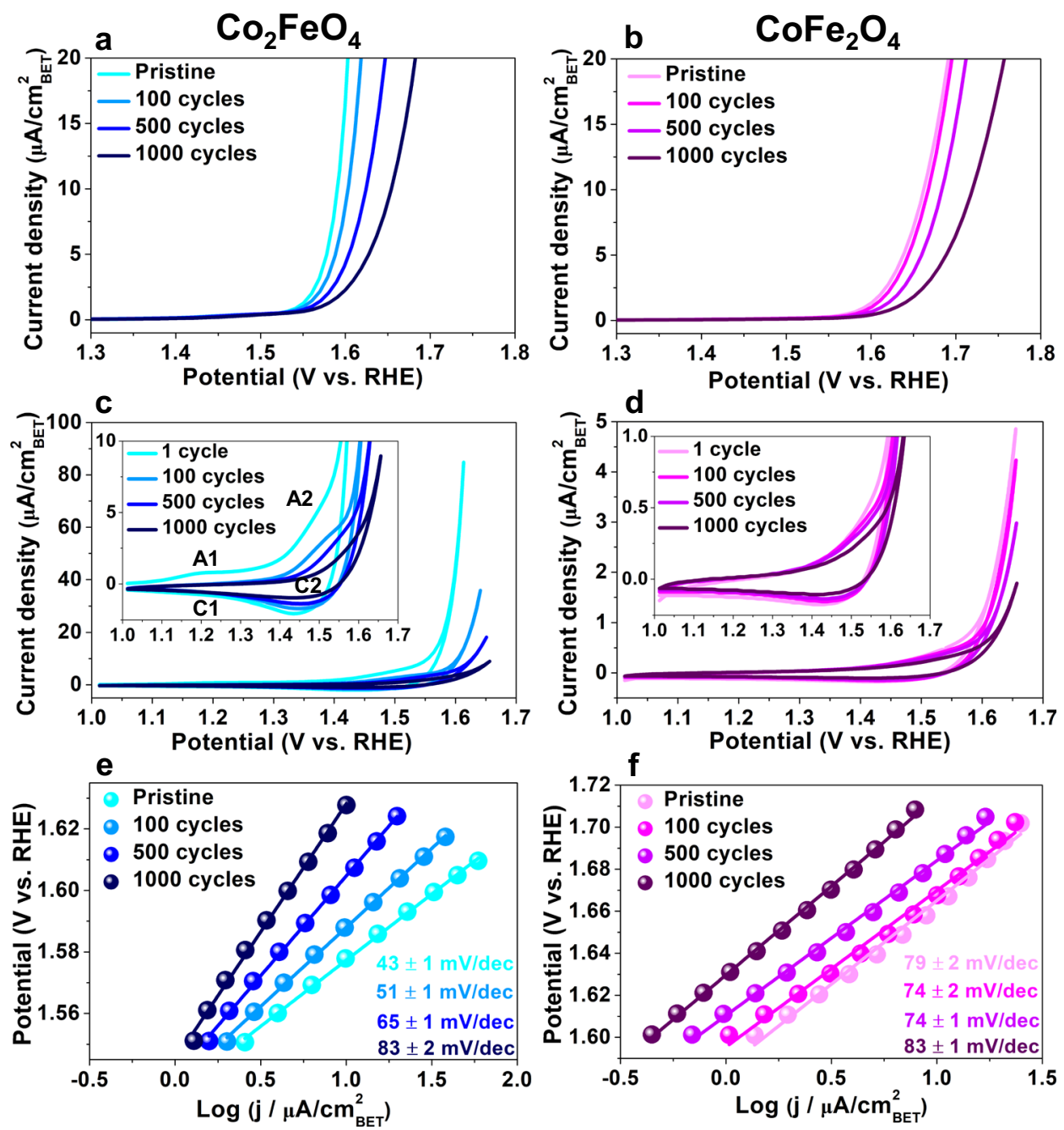

Fig. 1 OER activity of $\mathbf{C O}_{\mathbf{2}} \mathrm{FeO}_{\mathbf{4}}$ and $\mathrm{CoFe}_{\mathbf{2}} \mathbf{O}_{\mathbf{4}}$ nanoparticles. a, b Linear sweep voltammetry (LSV) curves recorded at a scan rate of $10 \mathrm{mV} / \mathrm{s}$ in $1.0 \mathrm{M} \mathrm{KOH}$ on glassy carbon electrodes deposited with $\mathrm{Co}_{2} \mathrm{FeO}_{4}$ and $\mathrm{CoFe}_{2} \mathrm{O}_{4}$ nanoparticles in the pristine state and after 100,500 and 1000 cycles of cyclic voltammetry (CV) measurements, c, d CVs of $\mathrm{CO}_{2} \mathrm{FeO}_{4}$ and $\mathrm{CoFe}_{2} \mathrm{O}_{4}$ after one, 100, 500 and 1000 cycles recorded at a scan rate of $50 \mathrm{mV} / \mathrm{s}$ in $1.0 \mathrm{M}$ $\mathrm{KOH}$ under OER conditions, e, $\mathbf{f}$ Tafel slopes of $\mathrm{CO}_{2} \mathrm{FeO}_{4}$ and $\mathrm{CoFe}_{2} \mathrm{O}_{4}$ in the pristine and after 100, 500 and 1000 cycles, derived from the LSV curves in a, b. Source data are provided as a Source Data file. The error bars of Tafel slopes in $\mathbf{e}$, $\mathbf{f}$ were measured by linear curve fitting.

the first $\mathrm{CV}$ cycle, two broad anodic peaks are observed at $\sim 1.19 \mathrm{~V}$ (A1) and $\sim 1.48 \mathrm{~V}$ (A2), possibly corresponding to the oxidation process of $\mathrm{Co}(\mathrm{II}) / \mathrm{Co}$ (III) and $\mathrm{Co}(\mathrm{III}) / \mathrm{Co}(\mathrm{IV})$, respectively ${ }^{26,27}$. The cathodic sweep exhibits a relatively strong cathodic peak at $\sim 1.44 \mathrm{~V}(\mathrm{C} 2)$, which is usually attributed to the $\mathrm{Co}(\mathrm{IV}) / \mathrm{Co}$ (III) couple in $\mathrm{Co}_{3} \mathrm{O}_{4}{ }^{26-29}$. The cathodic peak $\mathrm{Cl}$ at $\sim 1.1 \mathrm{~V}$ for the $\mathrm{Co}(\mathrm{II}) / \mathrm{Co}$ (III) process $^{26,27}$ is almost negligible after the first $\mathrm{CV}$ cycle, suggesting that the $\mathrm{Co}(\mathrm{II}) / \mathrm{Co}$ (III) process is likely not to be fully reversible. Additionally, the A2 and C2 peaks become less pronounced and nearly indiscernible after 1000 cycles, which indicates that the $\mathrm{Co}(\mathrm{III}) / \mathrm{Co}(\mathrm{IV})$ oxidation is likely irreversible. The gradual formation of irreversible $\mathrm{Co}$ (III) and $\mathrm{Co}(\mathrm{IV})$ surface species possibly results in the A2 peak gradually shifting to higher potentials, which leads to the increased Tafel slope (Fig. 1e $)^{30}$. In comparison with $\mathrm{Co}_{2} \mathrm{FeO}_{4}$, nearly no redox couples were observed for $\mathrm{CoFe}_{2} \mathrm{O}_{4}$, with a slight anodic shift after 1000 cycles (dark purple curve, insert in Fig. 1d), most likely suggesting the occurrence of an irreversible oxidation process.

Oxidation state on the surfaces. To investigate the reasons for the activity changes of $\mathrm{Co}_{2} \mathrm{FeO}_{4}$ and $\mathrm{CoFe}_{2} \mathrm{O}_{4}$, we first performed XPS to examine the oxidation state of $\mathrm{Co}$ and $\mathrm{Fe}$ on the surface of
$\mathrm{Co}_{2} \mathrm{FeO}_{4}$ and $\mathrm{CoFe}_{2} \mathrm{O}_{4}$ in their pristine state as well as after 100, 500 , and 1000 cycles. XPS measures the average oxidation state of approx. $100 \mu \mathrm{m} \times 100 \mu \mathrm{m} \times 5 \mathrm{~nm}$ of the surface region of the nanoparticles deposited on glassy carbon. Given the closeness of $2 p_{1 / 2}$ and $2 p_{3 / 2}$ peak locations for $\mathrm{Co}(\mathrm{II}), \mathrm{Co}(\mathrm{III})$ and $\mathrm{Co}(\mathrm{IV})^{31-34}$, the satellite features and their intensity change during OER, i.e., $786.5 \mathrm{eV}$ for $\mathrm{CoO}$-like $\mathrm{Co}(\mathrm{II})^{35}$ and $789.5 \mathrm{eV}$ for $\mathrm{Co}_{3} \mathrm{O}_{4}$-like $\mathrm{Co}$ (II, III), were analysed (peak fitting shown in Supplementary Fig. 6a). We can see from Fig. 2a that the intensity of CoO-like $\mathrm{Co}(\mathrm{II})$ satellite features decreases after 100 cycles, suggesting the oxidation of $\mathrm{Co}$ (II) to $\mathrm{Co}(\mathrm{III})$. As the number of $\mathrm{CV}$ cycles increases, the contribution of $\mathrm{CoO}$-like $\mathrm{Co}$ (II) decreases significantly, and $\mathrm{Co}_{3} \mathrm{O}_{4}$-like $\mathrm{Co}$ increases (as indicated by the depth analysis using peak deconvolution of the Co $2 p$ peak $^{35}$ shown in Supplementary Fig. 6b). Our CV data for $\mathrm{Co}_{2} \mathrm{FeO}_{4}$, shown in Fig. 1c, indicate an irreversible oxidation of $\mathrm{Co}(\mathrm{II}) / \mathrm{Co}$ (III) in the first cycle and of $\mathrm{Co}(\mathrm{III}) / \mathrm{Co}(\mathrm{IV})$ after 1000 cycles. While the presence of $\mathrm{Co}(\mathrm{IV})$ is difficult to be confirmed by XPS, the possibility cannot be excluded since the spectrum of $\mathrm{Co}_{3} \mathrm{O}_{4}$-like $\mathrm{Co}$ is similar to that of $\mathrm{CoO}_{2}$-like $\mathrm{Co}(\mathrm{IV})^{36}$. Thus, we conclude that $\mathrm{Co}(\mathrm{III})$ and $\mathrm{Co}(\mathrm{II})$ are present on the surface of $\mathrm{Co}_{2} \mathrm{FeO}_{4}$ after 100 and 500 cycles, while $\mathrm{Co}(\mathrm{III})$ and $\mathrm{Co}(\mathrm{IV})$ are likely present 

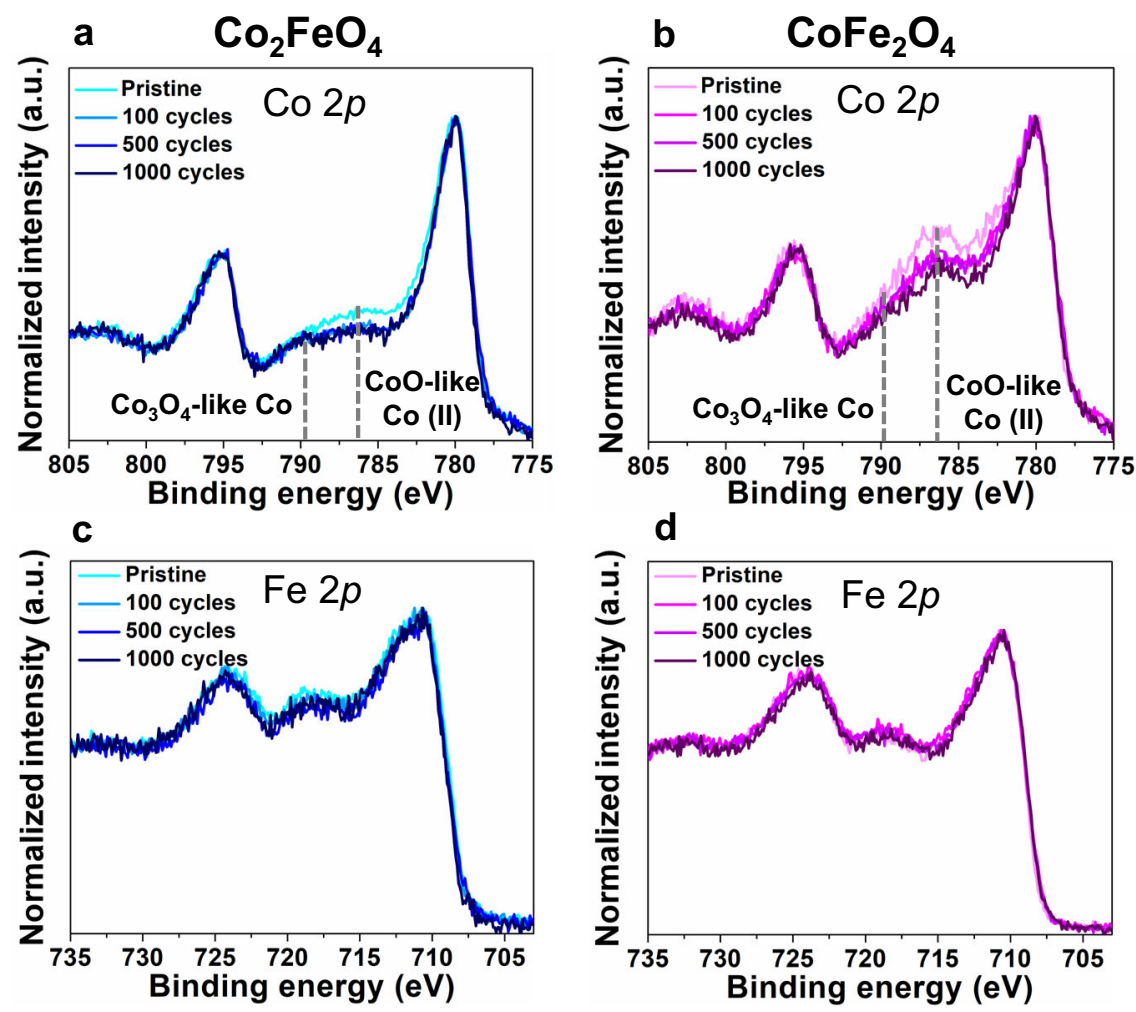

Fig. 2 Surface oxidation state of $\mathbf{C O}_{2} \mathbf{F e O}_{\mathbf{4}}$ and $\mathbf{C o F e}_{\mathbf{2}} \mathbf{O}_{\mathbf{4}}$ during OER. X-ray photoelectron spectra of a, $\mathbf{b}$ Co $2 p$ and $\mathbf{c}$, $\mathbf{d}$ Fe $2 p$ levels of $\mathrm{Co}_{2} \mathrm{FeO}{ }_{4}$ and $\mathrm{CoFe}_{2} \mathrm{O}_{4}$ in the pristine state and after 100, 500 and 1000 cycles. The dashed lines indicate the satellite features of $\mathrm{Co}_{3} \mathrm{O}_{4}$-like $\mathrm{Co}$ (II, III) and CoO-like Co(II). Source data are provided as a Source Data file.

after 1000 cycles. In contrast to $\mathrm{Co}_{2} \mathrm{FeO}_{4}$, the $\mathrm{CoO}$-like $\mathrm{Co}$ (II) satellite peaks of $\mathrm{CoFe}_{2} \mathrm{O}_{4}$, in Fig. $2 \mathrm{~b}$, decreases less significantly as the $\mathrm{CV}$ cycles increases. $\mathrm{Co}$ (III) seems to be present on the surface of $\mathrm{CoFe}_{2} \mathrm{O}_{4}$ after 500 and 1000 cycles, as shown in Supplementary Fig. $6 c$. In addition to $\mathrm{Co}$, the $\mathrm{Fe} 2 p$ spectra, shown in Fig. 2b, d remains unchanged, indicating that $\mathrm{Fe}$ (III) is present on the surface of both $\mathrm{Co}_{2} \mathrm{FeO}_{4}$ and $\mathrm{CoFe}_{2} \mathrm{O}_{4}$ as the number of $\mathrm{CV}$ cycles increases, in agreement with observations in most previous studies ${ }^{4,13}$.

To further verify the irreversible change in the oxidation state of $\mathrm{Co}_{2} \mathrm{FeO}_{4}$ in their pristine state and after 1000 cycles, we performed XAS that allows spectral detection of a bulk volume of approx. $100 \mu \mathrm{m} \times 300 \mu \mathrm{m} \times 1 \mathrm{~mm}$ (penetration depth) of nanoparticles deposited on glassy carbon (Supplementary Note 1 and Supplementary Fig. 7). We observed a subtle shift of Co K-edge towards higher energy values (Supplementary Fig. 7a), possibly suggesting that only a small volume fraction, potentially on the surface regions, has an increase in oxidation state to $\mathrm{Co}(\mathrm{IV})$, which is in agreement with the XAS data of Calvillo et al. ${ }^{20}$. Additionally, more octahedrally coordinated and less tetrahedrally coordinated $\mathrm{Co}^{37}$ was observed after 1000 cycles (inset, Supplementary Fig. 7a). By relating XPS and electrochemical data (Figs. 1c and 2a), we, therefore, speculate that tetrahedrally coordinated $\mathrm{Co}$ (II) irreversibly oxidises to octahedrally coordinated $\mathrm{Co}(\mathrm{III})$ or (IV) in the course of 1000 cycles, yielding a decrease in activity.

Structural changes. Next, HRTEM was employed to evaluate the structural changes of the $\mathrm{Co}_{2} \mathrm{FeO}_{4}$ and $\mathrm{CoFe}_{2} \mathrm{O}_{4}$ nanoparticles after OER, first in their pristine state and then after 100 and 1000 cycles. Figure 3 a shows a background-subtracted HRTEM image of pristine $\mathrm{Co}_{2} \mathrm{FeO}_{4}$, viewed along the [001] zone axis. Interestingly, the interplanar spacing of $\mathrm{d}_{220}$ varies slightly in different regions, as presented in Fig. 3a (details in Supplementary Fig. 8). After 100 cycles, a distinct structural change occurs on the surface of $\mathrm{Co}_{2} \mathrm{FeO}_{4}$, as highlighted by the blue-dotted areas in Fig. $3 \mathrm{~b}$ (more HRTEM images shown in Supplementary Fig. 9a, b). The Fast Fourier filtered transform (FFT) images, shown in insets of Fig. $3 \mathrm{~b}$, indicate that the motifs observed on the surface (bluedotted region) are aligned at $45^{\circ}$ to the atomistic arrangement of the spinel structure. The reflection spots from the surface region (Fig. $3 \mathrm{~b}$, bottom inset) correspond well with $\beta-\mathrm{CoOOH}(\mathrm{R} \overline{3} \mathrm{~m}$, hexagonal $^{38}$, Supplementary Table 1$)$, which agrees with observations of a previous study ${ }^{19}$. Therefore, we hypothesise that epitaxial growth of $(\mathrm{Co}, \mathrm{Fe}) \mathrm{OOH}$ occurs on $\mathrm{Co}_{2} \mathrm{FeO}_{4}$, with an orientation relationship of (010) $\mathrm{Co}_{2} \mathrm{FeO}_{4} / /(1-101)(\mathrm{Co}, \mathrm{Fe}) \mathrm{OOH}$. A previous study proposed that $\mathrm{Co}^{\mathrm{II}}$ ions at the tetrahedral site are oxidised to form amorphous $\mathrm{Co}^{\mathrm{III}}$ oxyhydroxides ${ }^{16}$. Here, we observed crystalline $\mathrm{Co}^{\mathrm{III}}$ oxyhydroxides, possibly formed by crystallisation of the amorphous $\mathrm{Co}^{\mathrm{III}}$ oxyhydroxides in the absence of potentials and electrolytes (also under high vacuum in TEM). Furthermore, after 1000 cycles, a 5-6 nm surface region, highlighted by the dark-blue-dotted area in Fig. 3c (Supplementary Fig. 9c, d), undergoes a phase transformation, since it contains a distinct lattice fringe from the [112]-oriented $\mathrm{Co}_{2} \mathrm{FeO}_{4}$ spinel oxide. The reflection spots in the FFT image (Fig. 3c, bottom inset) match well with the $\mathrm{CoO}_{2}$ phase $(\mathrm{P} \overline{3} \mathrm{~m} 1$, hexagonal ${ }^{39}$, Supplementary Table 1), with an octahedrally coordinated $\mathrm{Co}$ (IV). The formation of $\mathrm{CoO}_{2}$ is also confirmed by additional reflection spots that correspond well to (11-20) $\mathrm{CoO}_{2}$ in the selected area electron diffraction (SAED) pattern after 1000 cycles (Supplementary Fig. 2f); the SAED pattern was recorded from a $500 \mathrm{~nm} \times 500 \mathrm{~nm}$ area containing more than 100 nanoparticles. We observed an increase in octahedrally coordinated Co by XANES (Supplementary Fig. 7a, inset), the presence of irreversible $\mathrm{Co}(\mathrm{IV})$ by electrochemical data (Fig. 1a) and possible 

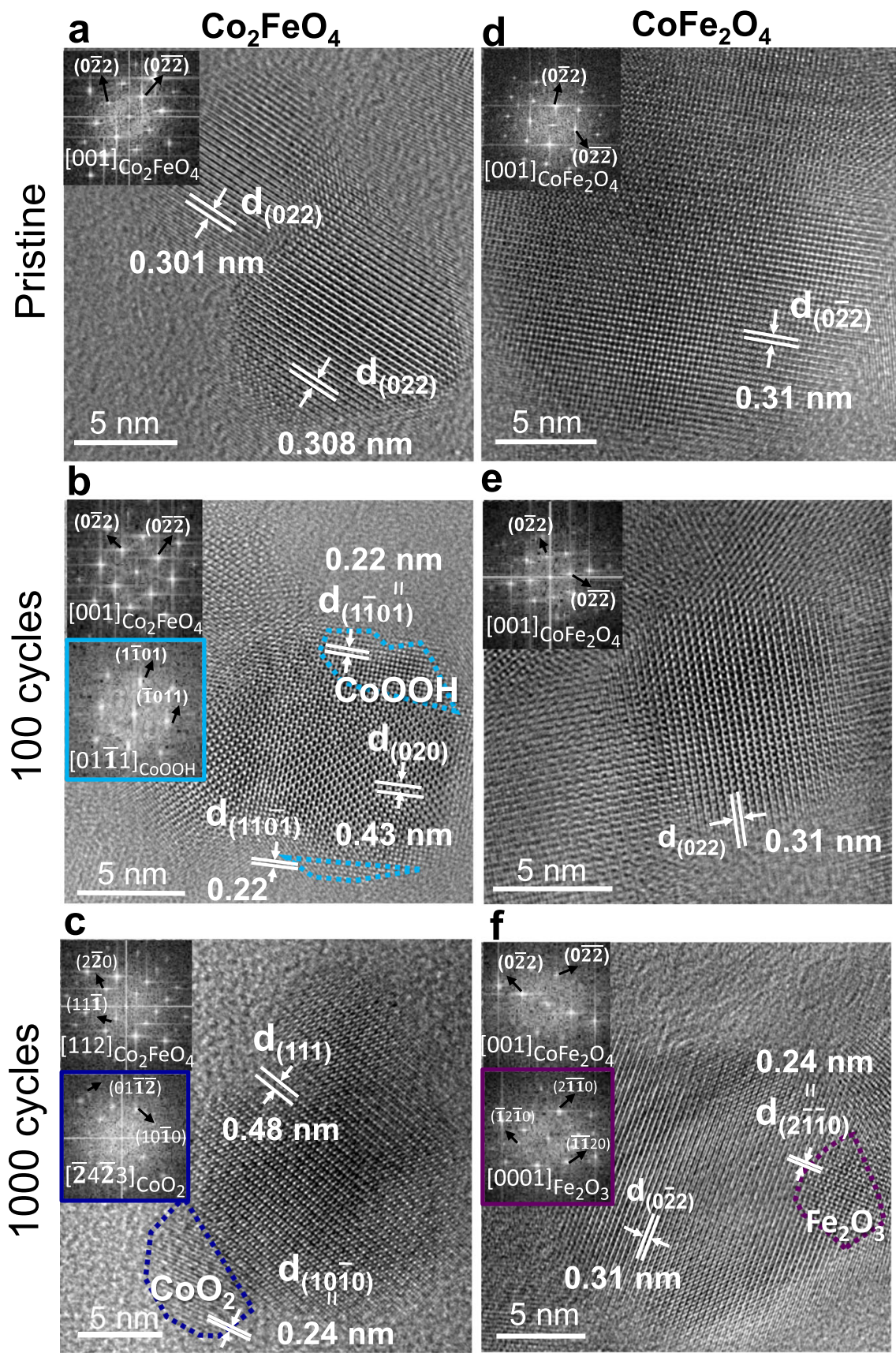

Fig. 3 Surface structural evolution of $\mathbf{C O}_{\mathbf{2}} \mathbf{F e O}_{\mathbf{4}}$ and $\mathbf{C o F e}_{\mathbf{2}} \mathbf{O}_{\mathbf{4}}$ during OER. High-resolution TEM images of $\mathrm{Co}_{2} \mathrm{FeO}_{4}$ and $\mathrm{CoFe}_{2} \mathrm{O}_{4} \mathbf{a}$, $\mathbf{d}$ in the pristine state, $\mathbf{b}, \mathbf{e}$ after 100 cycles and $\mathbf{c}, \mathbf{f}$ after 1000 cycles. The top insets in a-f were Fourier filtered transform images obtained from the centre of nanoparticles, and the bottom insets in $\mathbf{b}, \mathbf{c}$, $\mathbf{f}$ were recorded from the surface regions of nanoparticles highlighted by the dashed lines, indicating the occurrence of phase transformation on the surface regions of $\mathrm{CO}_{2} \mathrm{FeO}_{4}$ and $\mathrm{CoFe}_{2} \mathrm{O}_{4}$ during OER.

presence of Co (IV) by XPS (Fig. 2a). These results most likely imply an irreversible transformation towards $(\mathrm{Co}, \mathrm{Fe}) \mathrm{O}_{2}$ phase on the surface of $\mathrm{Co}_{2} \mathrm{FeO}_{4}$ after 1000 cycles. Additionally, $\mathrm{CoO}_{2}$ is the stable phase at higher potentials, in accordance with the Co Pourbaix diagram ${ }^{40}$.

In contrast with $\mathrm{Co}_{2} \mathrm{FeO}_{4}$, we observed no significant structural changes on the $\mathrm{CoFe}_{2} \mathrm{O}_{4}$ nanoparticle surface after 100 cycles (Fig. 3d, e). After 1000 cycles, a structural transformation of the surface of [001]-orientated $\mathrm{CoFe}_{2} \mathrm{O}_{4}$ spinel nanoparticles was discerned, as indicated by the purple dotted lines in Fig. $3 \mathrm{f}$ (Supplementary Fig. 9e, f). The reflection spots in the bottom inset of Fig. 3f correspond to either [412]-oriented $\mathrm{FeOOH}$ (I4/m, tetragonal ${ }^{41}$, Supplementary Table 1) or [0001]-orientated $\mathrm{Fe}_{2} \mathrm{O}_{3}$ phase $\left(\mathrm{R} \overline{\mathrm{C}} \mathrm{c}\right.$, hexagonal $\left.{ }^{42}\right)$, with the latter having a better fit. Also, the SAED pattern of $\mathrm{CoFe}_{2} \mathrm{O}_{4}$, in Supplementary Fig. 3f, reveals additional reflection spots after 1000 cycles, indicating the presence of (30-30) $\mathrm{Fe}_{2} \mathrm{O}_{3}$ or (202) $\mathrm{FeOOH}$. According to the Fe Pourbaix diagram ${ }^{43}, \mathrm{Fe}_{2} \mathrm{O}_{3}$ forms as the potential increases. Thus, the surface of inverse spinel $\mathrm{CoFe}_{2} \mathrm{O}_{4}$ is thought to undergo a phase transformation to the $(\mathrm{Fe}, \mathrm{Co})_{2} \mathrm{O}_{3}$ phase after 1000 cycles.

Notably, we observed an amorphous layer on the surfaces of aggregated $\mathrm{Co}_{2} \mathrm{FeO}_{4}$ and $\mathrm{CoFe}_{2} \mathrm{O}_{4}$ nanoparticles after 100, 500 and 1000 cycles (exemplified in Supplementary Fig. 10). However, these amorphous layers were most likely the result of carbon contamination under electron beam in TEM (details in Supplementary Fig. 10). 


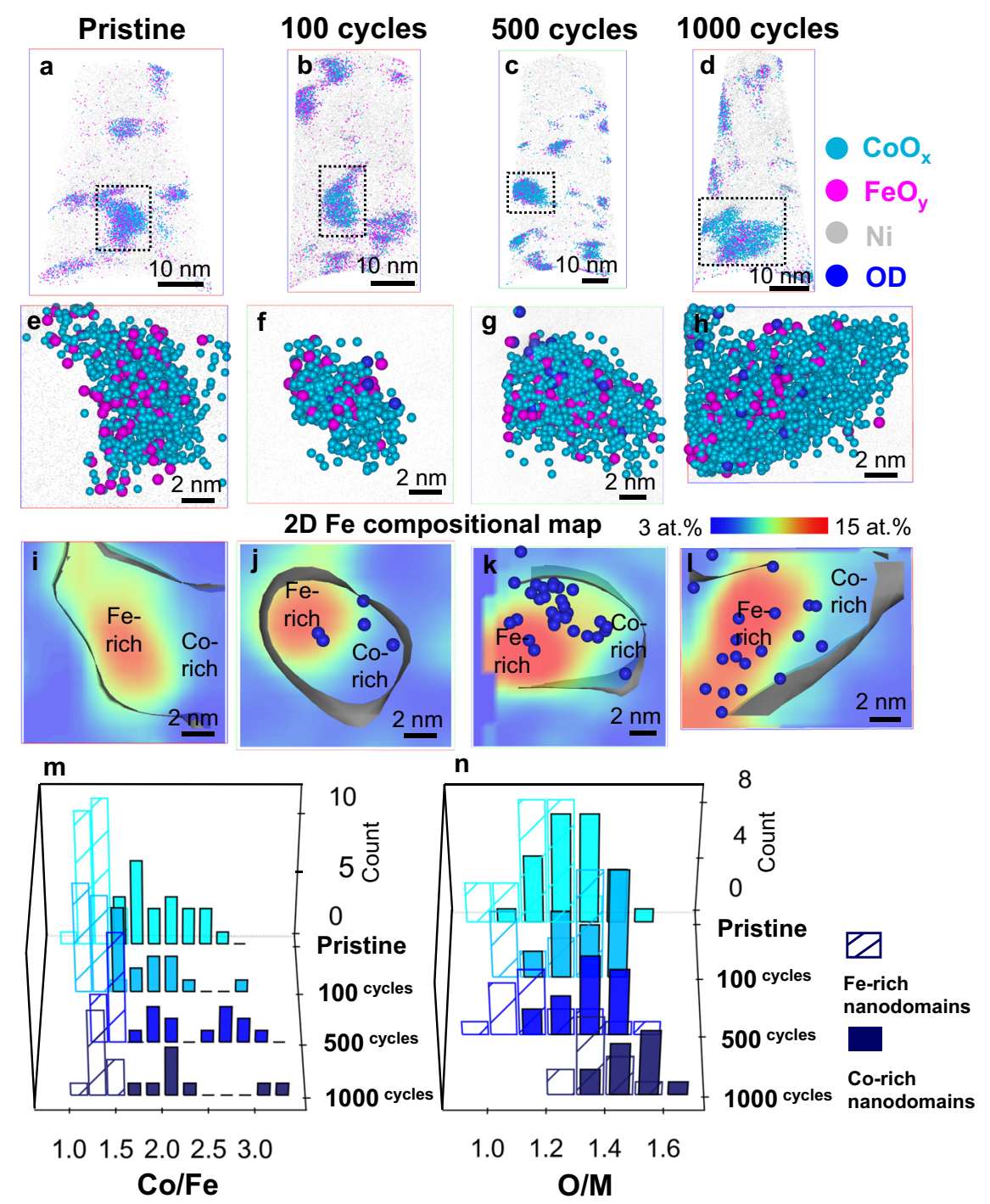

Fig. 4 Compositional evolution and elemental distribution of segregated $\mathbf{C O}_{\mathbf{2}} \mathbf{F e} \mathbf{O}_{\mathbf{4}}$ during $\mathbf{O E R}$. a-d $3 \mathrm{D}-\mathrm{APT}$ reconstruction of $\mathrm{CO}_{2} \mathrm{FeO} \mathrm{O}_{4}$ in the pristine state and after 100, 500 and 1000 cycles of $\mathrm{CV}$ showing the nanoparticles embedded in $\mathrm{Ni}$ matrix, $\mathbf{e}-\mathbf{h} 3 \mathrm{D}$ atom maps of segregated $\mathrm{Co}_{2} \mathrm{FeO}_{4}$ nanoparticles in the pristine state and after 100, 500 and 1000 cycles, selected from dashed line region in a-d ( $\mathbf{f}$ displayed in the top-down view of $\mathbf{b}$ ), and i-I 2D Fe compositional maps of the same nanoparticles in $\mathbf{e}-\mathbf{h}$ showing the Co-rich and Fe-rich nanodomains, compositional histograms of $\mathbf{m}$ Co/Fe ratios and $\mathbf{n} \mathrm{O} / \mathrm{M}$ ratios $(\mathrm{M}=\mathrm{Co}+\mathrm{Fe})$ in the Fe-rich and $\mathrm{Co}$-rich regions of segregated $\mathrm{Co}_{2} \mathrm{FeO}_{4}$ nanoparticles in a-d and Supplementary Fig. 12a-d. (Source data of Fig. $4 \mathrm{~m}, \mathrm{n}$ are provided as a Source Data file).

Compositional evolution and correlation with electrochemical performance. Although the $(\mathrm{Co}, \mathrm{Fe}) \mathrm{OOH}$, which is observed on the surface of $\mathrm{Co}_{2} \mathrm{FeO}_{4}$ (Fig. 3b), can be regarded as an active intermediate for $\mathrm{OER}^{27}$, the activity of $\mathrm{Co}_{2} \mathrm{FeO}_{4}$ decreased after 100 cycles (Fig. 1a, e). The cause of the decrease in the OER activity of $\mathrm{Co}_{2} \mathrm{FeO}_{4}$ (Fig. 1a, e) at the beginning of OER remains unclear. Other factors, such as chemical composition change, potentially lead to decreases in OER activity. Therefore, we used $\mathrm{APT}^{44}$, a mass-spectrometry technique with sub-nanometre spatial resolution in three dimensions ${ }^{45,46}$, to investigate the compositional evolution of oxide nanoparticles after OER. All electrochemical measurements were carried out in proton-free, deuterated electrolyte (i.e., $1.0 \mathrm{M} \mathrm{KOD}$ in $\mathrm{D}_{2} \mathrm{O}$ in order to use APT to examine the distribution of hydroxyl groups after $\mathrm{OER}^{47}$.

Figure $4 \mathrm{a}$ exemplifies a cross-sectional atom map of pristine $\mathrm{Co}_{2} \mathrm{FeO}_{4}$ nanoparticles embedded in a $\mathrm{Ni}$ matrix (APT specimen preparation is detailed in Supplementary Note 2/Supplementary Fig. 11 and additional APT data is shown in Supplementary
Fig. 12a). The oxide nanoparticles were detected by APT in the form of $\mathrm{O}$ ions and $\mathrm{Co}$ - and $\mathrm{Fe}$ - containing complex molecular ions (see mass spectra in Supplementary Fig. 13). All Co- (in blue) and $\mathrm{Fe}$ - (in magenta) containing molecular ions were shown as $\mathrm{CoO}_{\mathrm{x}}$ and $\mathrm{FeO}_{\mathrm{y}}$ respectively, in Fig. $4 \mathrm{a}$ (separate $\mathrm{Co}, \mathrm{Fe}, \mathrm{O}$ and $\mathrm{Ni}$ atom maps are shown in Supplementary Fig. 14). Our detailed APT analysis of 48 pristine $\mathrm{Co}_{2} \mathrm{FeO}_{4}$ nanoparticles (Fig. $4 \mathrm{a}$ and Supplementary Fig. 12a) reveals that 26 of them have nanoscale compositional modulation, while the remaining 22 exhibits a relatively uniform elemental distribution, as exemplified by Figs. $4 \mathrm{e}$ and $5 \mathrm{a}$, selected from the black and red dashed boxes in Fig. 4a and Supplementary Fig. 12a, respectively; we term these nanoparticles 'segregated' and 'non-segregated' $\mathrm{Co}_{2} \mathrm{FeO}_{4}$ nanoparticles, respectively. The 2D Fe composition map (Fig. 4i), plotted from the nanoparticle data of Fig. 4e, clearly reveals separate Fe-rich and Co-rich nanodomains, whose dimensions are in the range of $4-5 \mathrm{~nm}$, in the segregated pristine $\mathrm{Co}_{2} \mathrm{FeO}_{4}$ nanoparticle. In contrast, non-segregated pristine $\mathrm{Co}_{2} \mathrm{FeO}_{4}$ nanoparticles have uniformly distributed $\mathrm{Fe}$ and $\mathrm{Co}$ (Fig. 5a,e). 

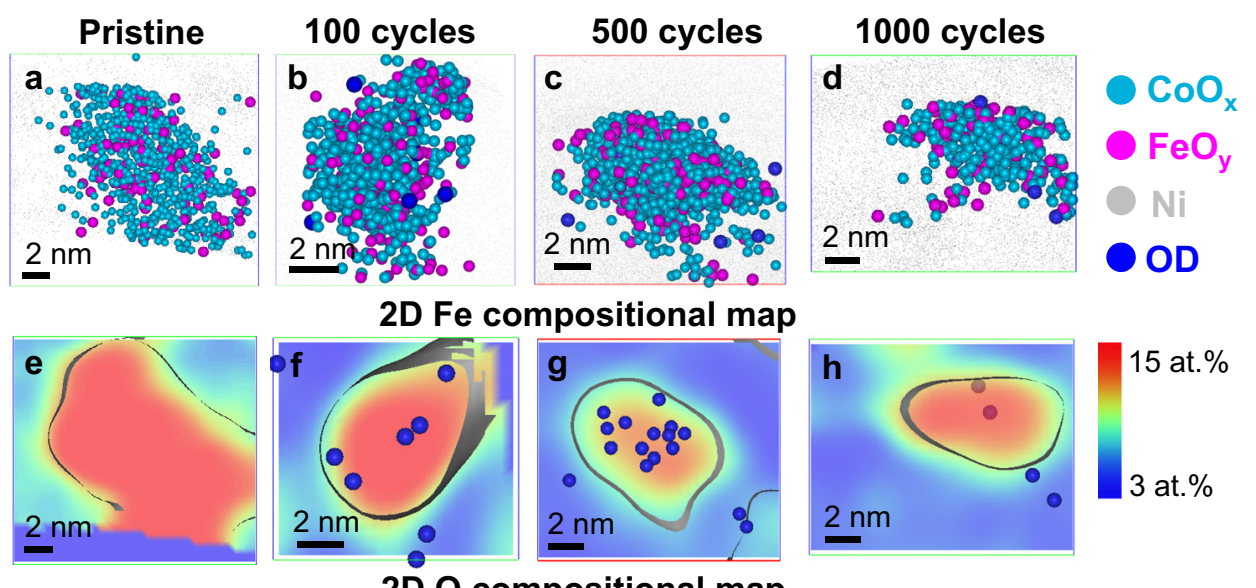

15 at. $\%$

2D O compositional map
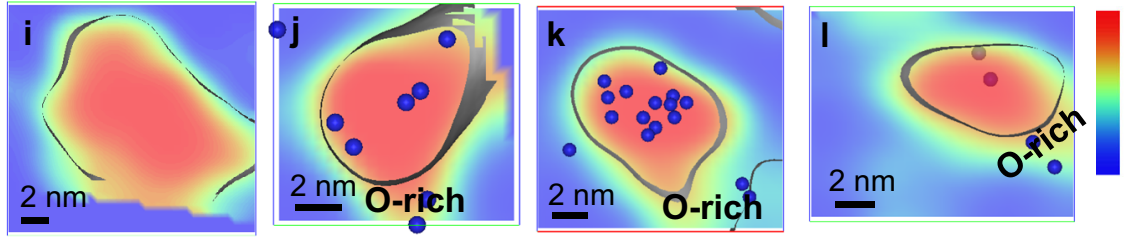

55 at. $\%$

m

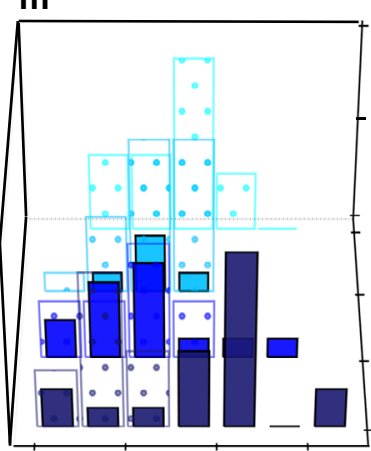

$\begin{array}{rrr}1.0 \quad 1.2 & 1.4 & 1.6 \\ & C o / F e\end{array}$
10
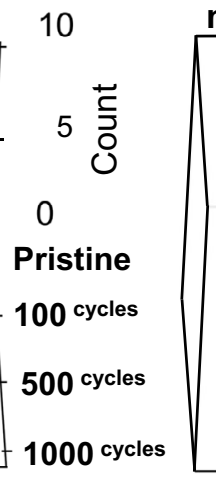

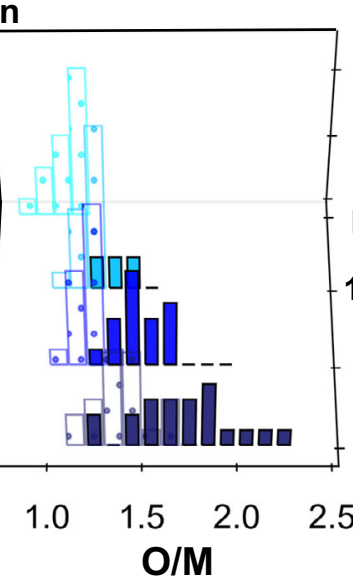

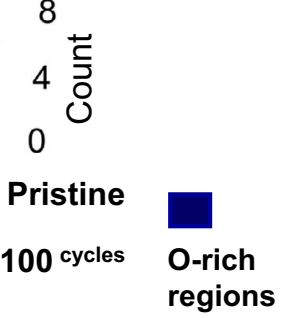

500 cycles

1000 cycles Bulk

3 at. $\%$

0 at. $\%$

Fig. 5 Compositional evolution and elemental distribution of non-segregated $\mathbf{C o}_{\mathbf{2}} \mathbf{F e} \mathbf{O}_{\mathbf{4}}$ during $\mathbf{O E R}$. a-d $3 \mathrm{D}$ atom maps, $2 \mathrm{D}$ compositional maps of e-h $\mathrm{Fe}$ and $\mathbf{i}-\mathbf{I} \mathrm{O}$ of non-segregated $\mathrm{Co}_{2} \mathrm{FeO}_{4}$ nanoparticles in the pristine state and after 100, 500 and 1000 cycles, compositional histograms of $\mathbf{m} \mathrm{Co} / \mathrm{Fe}$ ratios and $\mathbf{n} \mathrm{O} / \mathrm{M}$ ratios $\left(\mathrm{M}=\mathrm{Co}+\mathrm{Fe}\right.$ ) in the O-rich nanoregions and the bulk part of non-segregated $\mathrm{Co}_{2} \mathrm{FeO}_{4}$ nanoparticles in Fig. 4a-d and Supplementary Fig. 12a-d. (Source data of Fig. $5 \mathrm{~m}, \mathrm{n}$ are provided as a Source Data file).

The compositions of the Fe-rich and Co-rich nanodomains in pristine $\mathrm{Co}_{2} \mathrm{FeO}_{4}$, obtained by $1 \mathrm{D}$ composition profiles in Supplementary Figs. 15a and 16a and data from 25 segregated nanoparticles in Supplementary Fig. 12a, were plotted as composition histograms of $\mathrm{Co} / \mathrm{Fe}$ and oxygen $/(\mathrm{Co}+\mathrm{Fe})$ (termed $\mathrm{O} / \mathrm{M}$ ) ratios in Fig. $4 \mathrm{~m}, \mathrm{n}$. The average ratios of $\mathrm{Co} / \mathrm{Fe}$ and $\mathrm{O} / \mathrm{M}$ from all nanoparticles are detailed in Tables 1 and 2. Note that the oxygen content was normalised by the value measured by using $\mathrm{H}_{2}$ temperature-programmed reduction $\left(\mathrm{H}_{2} \mathrm{TPR}\right)$ and the effect of laser pulse energy on the measurement of oxide stoichiometry 48 was detailed in Supplementary Note 3 and Supplementary Figs. 22 and 23. The Fe-rich and Co-rich nanodomains have $\mathrm{Co} / \mathrm{Fe}$ ratios of $1.2 \pm 0.1$ and $2.2 \pm 0.1$, respectively, and $\mathrm{O} / \mathrm{M}$ ratios of $1.2 \pm 0.1$ and $1.3 \pm 0.1$, respectively. Thus, although the Fe-rich and Co-rich nanodomains have similar oxygen contents, they have significantly different $\mathrm{Co} / \mathrm{Fe}$ ratios; the stoichiometry of the 'segregated' $\mathrm{Co}_{2} \mathrm{FeO}_{4}$ nanoparticle is $\mathrm{Co}_{2.1} \mathrm{Fe}_{0.9} \mathrm{O}_{3.9}$ in the Co-rich nanodomain and $\mathrm{Co}_{1.65} \mathrm{Fe}_{1.35} \mathrm{O}_{3.6}$ for the Fe-rich nanodomain. Similarly, the stoichiometry of the non-segregated nanoparticles is $\mathrm{Co}_{1.7} \mathrm{Fe}_{1.3} \mathrm{O}_{3.3}$ (based on values given in Tables 1 and 2). The formation of Fe-rich and Co-rich nanodomains in the pristine $\mathrm{Co}_{2} \mathrm{FeO}_{4}$ nanoparticles is most likely the result of spinodal decomposition that is driven by the miscibility gap in the composition range $0.37<\mathrm{Co} /(\mathrm{Co}+\mathrm{Fe})<0.9$ at temperatures below $700{ }^{\circ} \mathrm{C}^{21,22}$. According to the $\mathrm{CoFe}_{2} \mathrm{O}_{4}$ $\mathrm{Co}_{3} \mathrm{O}_{4}$ phase diagram ${ }^{21,22}, \mathrm{Co}_{2} \mathrm{FeO}_{4}$ is expected to decompose to $\mathrm{Co}_{1.4} \mathrm{Fe}_{1.6} \mathrm{O}_{4}(\mathrm{Co} / \mathrm{Fe}=0.875)$ and $\mathrm{Co}_{2.4} \mathrm{Fe}_{0.6} \mathrm{O}_{4}(\mathrm{Co} / \mathrm{Fe}=4)$. The discrepancy of compositions between our study and previous work possibly arises from the fact that these nanoparticles do not reach thermodynamic equilibrium after synthesis, and we expect the phase stability of nanoparticles to deviate from that of bulk materials in previous studies ${ }^{21,22}$. Despite this, we unambiguously reveal nanoscale compositional modulation of $\mathrm{Co}_{2} \mathrm{FeO}_{4}$ nanoparticles. In contrast, we did not observe any segregation for the $\mathrm{CoFe}_{2} \mathrm{O}_{4}$ nanoparticles, as shown in the atom map of Fig. 6a and the $2 \mathrm{D}$ Fe compositional map of Fig. $6 \mathrm{e}$, since the $\mathrm{Co} /(\mathrm{Co}+\mathrm{Fe})$ ratio (0.33) falls outside the composition window of spinodal decomposition ${ }^{21,22}$.

Next, we examined elemental redistribution of 'segregated' $\mathrm{Co}_{2} \mathrm{FeO}_{4}$ nanoparticles after 100, 500 and 1000 cycles under OER 

counts in all analysed datasets.
$\mathrm{CO}_{2} \mathrm{FeO}_{4}$

\section{Segregated}

Co/Fe

Pristine

100 cycles

500 cycles
1000 cycles
Fe-rich Nanodomains

$1.2 \pm 0.1$

$1.3 \pm 0.1$

$1.5 \pm 0.1$

$1.4 \pm 0.1$

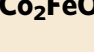

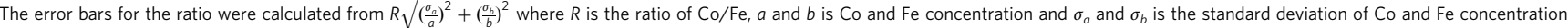
(Source data is provided in a Source Data file).

Table 2 Average $\mathrm{O} / \mathrm{M}$ ratios in $\mathrm{CO}_{2} \mathrm{FeO}_{4}$ and $\mathrm{CoFe}_{2} \mathrm{O}_{4}$ nanoparticles during OER calculated by the total number of $\mathrm{O}$ and $(\mathrm{Co}+\mathrm{Fe})$ counts in all analysed datasets.

\begin{tabular}{|c|c|c|c|c|c|c|}
\hline \multirow[b]{2}{*}{$0 / M$} & \multicolumn{4}{|l|}{$\mathrm{CO}_{2} \mathrm{FeO}_{4}$} & \multicolumn{2}{|l|}{$\mathrm{CoFe}_{2} \mathrm{O}_{4}$} \\
\hline & Fe-rich nanodomains & Co-rich nanodomains & Bulk & O-rich regions & Bulk & O-rich regions \\
\hline Pristine & $1.2 \pm 0.1$ & $1.3 \pm 0.1$ & $1.1 \pm 0.1$ & - & $1.2 \pm 0.1$ & - \\
\hline 100 cycles & $1.3 \pm 0.1$ & $1.4 \pm 0.1$ & $1.2 \pm 0.1$ & $1.4 \pm 0.1$ & $1.2 \pm 0.1$ & - \\
\hline 500 cycles & $1.3 \pm 0.1$ & $1.4 \pm 0.1$ & $1.2 \pm 0.1$ & $1.5 \pm 0.1$ & $1.3 \pm 0.1$ & $1.7 \pm 0.1$ \\
\hline 1000 cycles & $1.5 \pm 0.1$ & $1.6 \pm 0.1$ & $1.3 \pm 0.1$ & $1.8 \pm 0.1$ & $1.3 \pm 0.1$ & $1.8 \pm 0.1$ \\
\hline
\end{tabular}

conditions (Fig. 4b-d, f-h). Importantly, we observed that the hydroxyl groups, shown as dark blue spheres in $2 \mathrm{D} \mathrm{Fe}$ compositional profiles of Fig. $4 \mathrm{j}-\mathrm{l}$, are preferentially located at the interface between Fe-rich and Co-rich nanodomains after 100 and 500 cycles, and dominantly in Fe-rich regions after 1000 cycles. The trapping of hydroxyl groups at the interface of two nanodomains is most likely induced by the elastic strain that results from the difference in lattice constants of these two domains. This is confirmed by the difference in interplanar spacing of $\mathrm{d}_{220}$ measured from two regions of pristine $\mathrm{Co}_{2} \mathrm{FeO}_{4}$ nanoparticles (Fig. 3a and Supplementary Fig. 8), which is ascribed to the difference in $\mathrm{Co} / \mathrm{Fe}$ content of these nanodomains (similar to the difference of lattice constants of pristine $\mathrm{Co}_{2} \mathrm{FeO}_{4}$ and $\mathrm{CoFe}_{2} \mathrm{O}_{4}$ observed by XRD shown in Supplementary Fig. 1). The hydroxyl groups can be considered as 'fingerprints' that indicate the regions where OER occurs ${ }^{49}$. Therefore, we hypothesise that interfaces between two nanodomains provide active sites and accelerate OER kinetics, thereby possibly contributing to the high OER activity of pristine $\mathrm{Co}_{2} \mathrm{FeO}_{4}$ nanoparticles.

More importantly, we observed a dramatic compositional change within the nanodomains of $\mathrm{Co}_{2} \mathrm{FeO}_{4}$ as the number of $\mathrm{CV}$ cycles increased (Supplementary Figs. 15b-d and 16b-d along with all other nanoparticle data in Supplementary Fig. 12b-d were summarised in Fig. 4m, $\mathrm{n}$ and Tables 1 and 2; the number of nanoparticles for composition histograms was detailed in Supplementary Table 2). Specifically, the $\mathrm{Co} / \mathrm{Fe}$ ratio in the Corich nanodomains remained at $\sim 2.2$ after 100 cycles but increased to $\sim 2.8$ after 500 cycles and 2.9 after 1000 cycles (Table 1 ). This result suggests a gradual $\mathrm{Fe}$ loss in the Co-rich nanodomains during OER (as also confirmed by $1 \mathrm{D}$ profiles of atomic counts in Supplementary Fig. 15e-h). The O/M ratio in Co-rich nanodomains increases gradually to $\sim 1.4$ after 100 and 500 cycles, and $\sim 1.6$ after 1000 cycles (Table 2 and Fig. 4n). The O/M ratio in the
Fe-rich nanodomains also increases to $\sim 1.5$ after 1000 cycles. The gradual increase in the $\mathrm{O} / \mathrm{M}$ ratio of the segregated $\mathrm{Co}_{2} \mathrm{FeO}_{4}$ nanoparticles in both Co-rich and Fe-rich nanodomains suggests the occurrence of oxidation in both nanodomains. A more pronounced Fe loss was observed in the Co-rich nanodomains compared to that of the Fe-rich nanodomains (Table 1 and Fig. $4 \mathrm{~m}$ ), possibly suggesting that OER occurs more rigorously in the Co-rich nanodomains than that in $\mathrm{Fe}$-rich nanodomains.

For the 'non-segregated' $\mathrm{Co}_{1.7} \mathrm{Fe}_{1.3} \mathrm{O}_{3.3}$ nanoparticles, we observed 2-3 nm oxygen-rich surface regions after 100 cycles by comparing the $2 \mathrm{D}$ Fe and $\mathrm{O}$ compositional maps (Fig. $5 \mathrm{f}, \mathrm{j}$ ) of the same nanoparticle. The $\mathrm{O} / \mathrm{M}$ ratio in the oxygen-rich regions increases from $1.4 \pm 0.2$ after 100 cycles to $1.8 \pm 0.2$ after 1000 cycles (see Table 2 and Fig. 5n, which was measured from the 1D concentration profiles in Supplementary Figs. 17 and 18, and all other nanoparticle data in Supplementary Fig. 12b-d). Based on the $\mathrm{O} / \mathrm{M}$ ratios listed in Table 2, we speculate that the oxygen-rich surface regions possibly correspond to $(\mathrm{Co}, \mathrm{Fe}) \mathrm{OOH}$ after 100 cycles, and ( $\mathrm{Co}, \mathrm{Fe}) \mathrm{O}_{2}$ after 1000 cycles, as observed by HRTEM (Fig. 3b, c and Supplementary Fig. 9a-d). Additionally, we observed a subtle Fe loss in the oxygen-rich region after 1000 cycles, as the $\mathrm{Co} / \mathrm{Fe}$ ratio increases (Table 1 and Fig. $5 \mathrm{~m}$ ). Previous work also observed an increasing $\mathrm{Co} / \mathrm{Fe}$ ratio on the surface of $\mathrm{CoFe}_{0.75} \mathrm{Al}_{1.5} \mathrm{O}_{4}$ by electron energy loss spectroscopy ${ }^{5}$, attributing it to the formation of Co oxyhydroxide. Here, we speculate that the increasing $\mathrm{Co} / \mathrm{Fe}$ ratio is most likely due to $\mathrm{Fe}$ loss during structural transformation under the OER conditions. Concurrent structural transformation and $\mathrm{Fe}$ dissolution most likely lead to the overall reduction in OER activity of $\mathrm{Co}_{2} \mathrm{FeO}_{4}$ after 100 and 500 cycles (Fig. 1a, c). After 1000 cycles, surface formation of stable $\left(\mathrm{Co}^{\mathrm{IV}}, \mathrm{Fe}^{\mathrm{III}}\right) \mathrm{O}_{2}$ further decreases the activity of $\mathrm{Co}_{2} \mathrm{FeO}_{4}$.

For comparison with $\mathrm{Co}_{2} \mathrm{FeO}_{4}$, the compositional changes of the $\mathrm{CoFe}_{2} \mathrm{O}_{4}$ nanoparticles after 100,500 and 1000 cycles are 


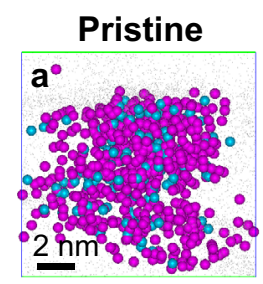

100 cycles

500 cycles
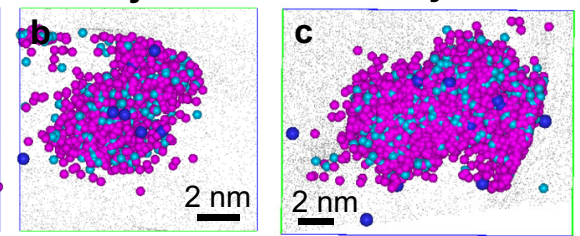

2D Fe compositional map
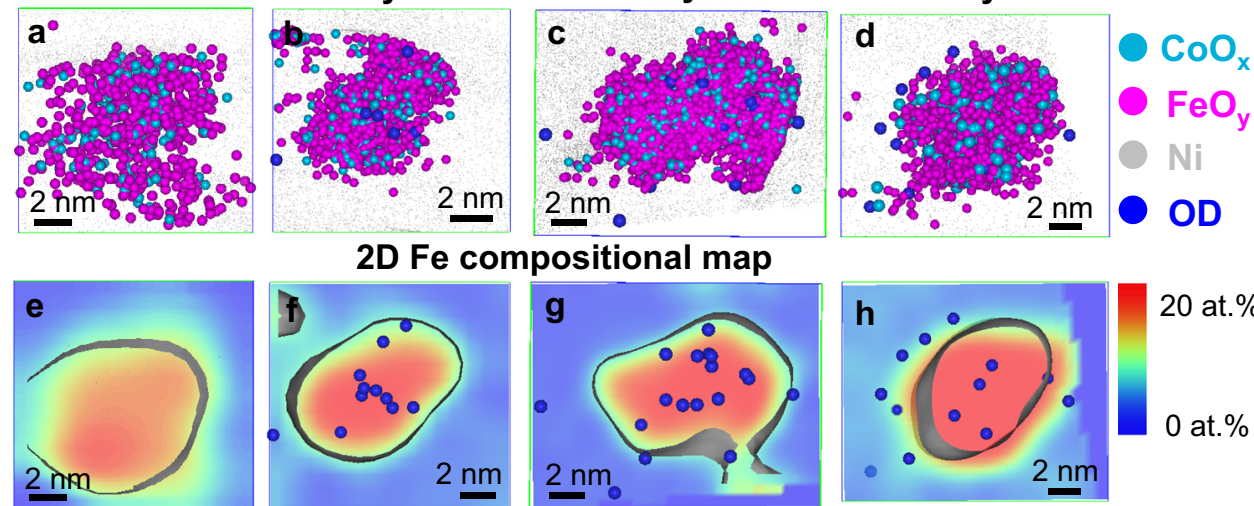

2D O compositional map
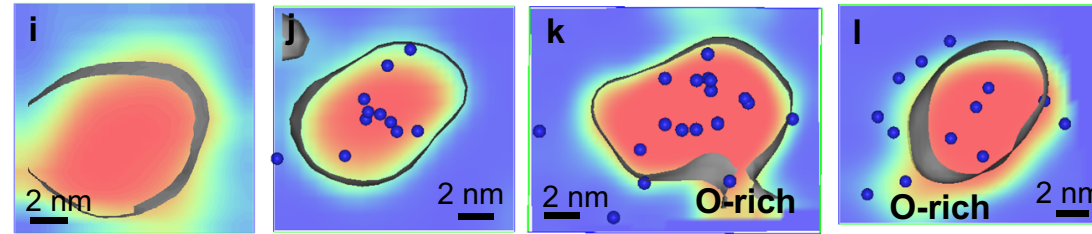

55 at. $\%$

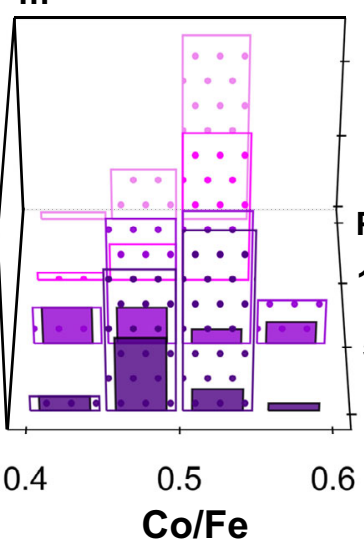

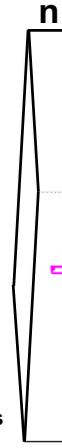

\section{0}

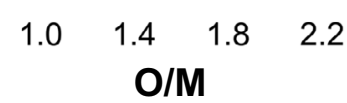

20

$10 \stackrel{\widetilde{0}}{0}$

0

Pristine

100 cycles

500 cycles

1000 cycles Bulk

2

Fig. 6 Compositional evolution and elemental distribution of $\mathbf{C o F e}_{\mathbf{2}} \mathbf{O}_{\mathbf{4}}$ during $\mathbf{O E R}$. a-d $3 \mathrm{D}$ atom maps, 2D compositional maps of $\mathbf{e}-\mathbf{h} \mathrm{Fe}$ and $\mathbf{i}-\mathbf{I} \mathrm{O}$ of non-segregated $\mathrm{CoFe}_{2} \mathrm{O}_{4}$ nanoparticles in the pristine state and after 100, 500 and 1000 cycles, combined compositional histograms of $\mathbf{m}$ Co/Fe ratios and $\mathbf{n} \mathrm{O} / \mathrm{M}$ ratios $\left(\mathrm{M}=\mathrm{Co}+\mathrm{Fe}\right.$ ) in the O-rich nanoregions and the bulk part of non-segregated $\mathrm{CoFe}_{2} \mathrm{O}_{4}$ nanoparticles in Supplementary Fig. 19a-d. (Source data of Fig. $6 \mathrm{~m}, \mathrm{n}$ are provided as a Source Data file).

provided in Fig. 6b-l. The oxide stoichiometry of pristine $\mathrm{CoFe}_{2} \mathrm{O}_{4}$ is measured as $\mathrm{CoFe}_{2} \mathrm{O}_{3.6}$, based on values in Tables 1 and 2 (measured from 39 nanoparticles in Supplementary Fig. 19a and Supplementary Table 2). No evident elemental redistribution was observed after 100 cycles, while $2-3 \mathrm{~nm}$ oxygen-rich regions were seen on the surface of $\mathrm{CoFe}_{2} \mathrm{O}_{4}$ after 500 and 1000 cycles, as indicated by the 2D Fe and $\mathrm{O}$ compositional maps in Fig. 6g, h, k, 1. The $\mathrm{O} / \mathrm{M}$ ratio in the oxygen-rich regions increased to $\sim 1.7$ after 500 cycles, reaching up to $\sim 1.8$ after 1000 cycles, while $\mathrm{Co} / \mathrm{Fe}$ increased only slightly (Tables 1 and 2 and Fig. $6 \mathrm{~m}, \mathrm{n}$, derived from 1D concentration profiles in Supplementary Figs. 20 and 21 and all other data in Supplementary Fig. 19b-d). The XPS and XANES data suggest that $\mathrm{Co}^{\mathrm{II}}$ was oxidised to $\mathrm{Co}^{\mathrm{III}}$ while $\mathrm{Fe}^{\mathrm{III}}$ remained stable even after 1000 cycles (Fig. 2 and Supplementary Fig. 7). Therefore, we speculate that the oxygen-rich regions possibly correspond to the $\left(\mathrm{Fe}^{\mathrm{III}}, \mathrm{Co}^{\mathrm{III}}\right)_{2} \mathrm{O}_{3}$ phase, as also observed by HRTEM (Fig. 3f and Supplementary Fig. 9e, f).

Electrochemical sub-processes during OER. To further understand the deactivation of both spinel oxide nanoparticles, we employed EIS to reveal the electrochemical sub-processes during OER. The Nyquist plots, in Fig. 7a, b, show two distorted semicircles for $\mathrm{Co}_{2} \mathrm{FeO}_{4}$, whereas one semicircle is observed for the inverse spinel $\mathrm{CoFe}_{2} \mathrm{O}_{4}$. The distribution of relaxation times for $\mathrm{Co}_{2} \mathrm{FeO}_{4}$ (inset of Fig. 7a) reveals three distinct peaks, and one peak is discerned for $\mathrm{CoFe}_{2} \mathrm{O}_{4}$ (inset of Fig. 7b). Figure 7c, d contain the resistances and capacitances for both spinel oxides in the pristine state and after 100, 500 and 1000 cycles (derived by equivalent circuit fitting ${ }^{50,51}$, more details in Supplementary Note 4 and Supplementary Figs. 24 and 25). The equivalent circuit for $\mathrm{Co}_{2} \mathrm{FeO}_{4}$, shown in Fig. $7 \mathrm{c}$, contains the double layer capacitor $\mathrm{C}_{1}$ and the pseudocapacitors $\mathrm{C}_{2}$ and $\mathrm{C}_{3}$. The corresponding pseudocapacitive properties are based on changing oxidation states of electrochemically accessible cobalt sites and adsorptive discharge of oxygen-containing species in the electrolyte $\mathrm{e}^{52,53}$. So, in course of a catalytic cycle, intermediate catalytic (re-)transformations occur via pseudocapacitive charging/discharging through the faradaic resistors $R_{1}$ and $R_{2}{ }^{54}$. In parallel, the OER reaction proceeds via $\mathrm{OH}^{-}$-to- $\mathrm{O}_{2}$ conversion steps at the solution side $e^{55}$. We can see from Fig. $7 c$ that the resistance increases with the number of $\mathrm{CV}$ cycles, particularly for 

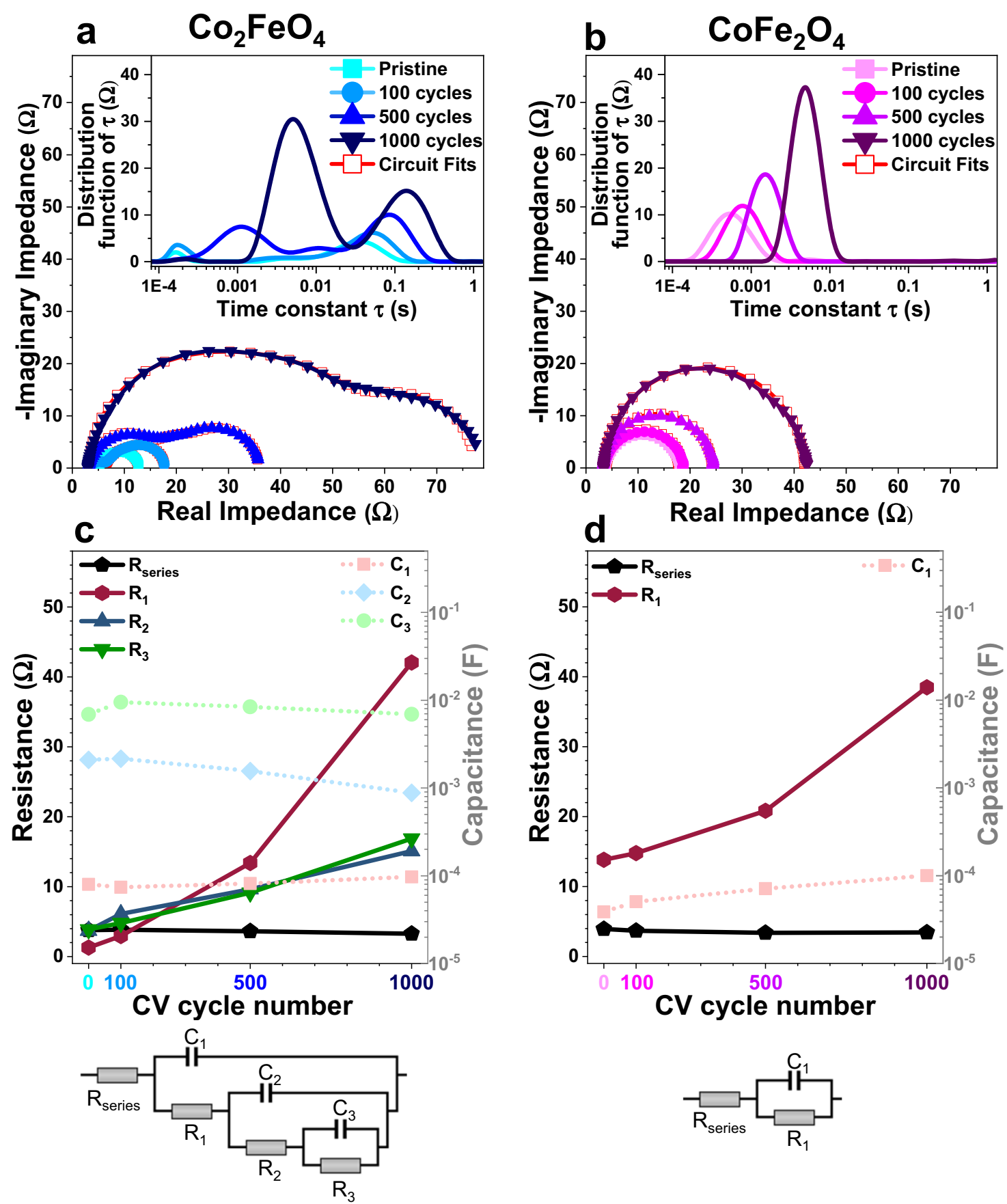

Fig. 7 Electrochemical sub-processes of $\mathbf{C O}_{\mathbf{2}} \mathbf{F e O}_{\mathbf{4}}$ and $\mathrm{CoFe}_{\mathbf{2}} \mathbf{O}_{\mathbf{4}}$ during OER. Electrochemical impedance spectroscopy data in complex plane representation (Nyquist plot) and determined distribution of relaxation times (insets) of electrodes covered by $\mathbf{a} \mathrm{Co}_{2} \mathrm{FeO}_{4}$ nanoparticles at $1.63 \mathrm{~V}$ vs. $\mathrm{RHE}$ $\left(\approx \mathrm{E}_{\mathrm{LSV} \text {,initial }}\left(6 \mathrm{~mA} / \mathrm{cm}^{2}\right.\right.$ geom $\left.)\right)$ and $\mathbf{b} \mathrm{CoFe}_{2} \mathrm{O}_{4}$ nanoparticles at $1.73 \mathrm{~V}$ vs. $\mathrm{RHE}\left(\approx \mathrm{E}_{\mathrm{LSV} \text {, initial }}\left(6 \mathrm{~mA} / \mathrm{cm}^{2}\right.\right.$ geom $\left.)\right)$ in the pristine state and after 100,500 and 1000 cycles. c, $\mathbf{d}$ Corresponding changes of the resistances (solid lines) and capacitances (dashed lines) as the number of CV cycles increases (obtained by equivalent circuit fitting to the displayed model circuits). Source data are provided as a Source Data file.

$\mathrm{R}_{1}$, accompanied by a slightly decreasing $\mathrm{C}_{2}$. This result suggests inhibited kinetics of adsorption of $\mathrm{OH}^{-}$and an occurrence of irreversible oxidation of $\mathrm{Co}$, which is consistent with our TEM and APT observation of structural transformation towards (Co, $\mathrm{Fe}) \mathrm{OOH}$ and $(\mathrm{Co}, \mathrm{Fe}) \mathrm{O}_{2}$ as the number of $\mathrm{CV}$ cycles increases. In contrast, no pseudocapacitive behaviour was observed for $\mathrm{CoFe}_{2} \mathrm{O}_{4}$ (Fig. 7b), which may relate to its low OER activity compared to $\mathrm{Co}_{2} \mathrm{FeO}_{4}$, as indicated by Tafel plots (Fig. 1e, f). For both $\mathrm{Co}_{2} \mathrm{FeO}_{4}$ and $\mathrm{CoFe}_{2} \mathrm{O}_{4}$, the increasing faradaic resistances (Fig. $7 \mathrm{c}, \mathrm{d}$ ) explain that the overpotential increases with the number of CV cycles (Fig. 1a, b), which is most likely arisen from irreversible structural transformation towards inactive phases, as revealed by our TEM (Fig. 3c, f and Supplementary Figs. 2f and 3f) and APT data (Tables 1 and 2).

\section{Discussion}

Our study demonstrates that the deactivation process of $\mathrm{Co}_{2} \mathrm{FeO}_{4}$ and $\mathrm{CoFe}_{2} \mathrm{O}_{4}$ is closely associated with their structural and compositional evolution during OER, as schematically summarised in Fig. 8. Our APT data (Fig. 4i, m) unprecedentedly reveals 'segregated' $\mathrm{Co}_{2} \mathrm{FeO}_{4}$ whose compositional modulation is 


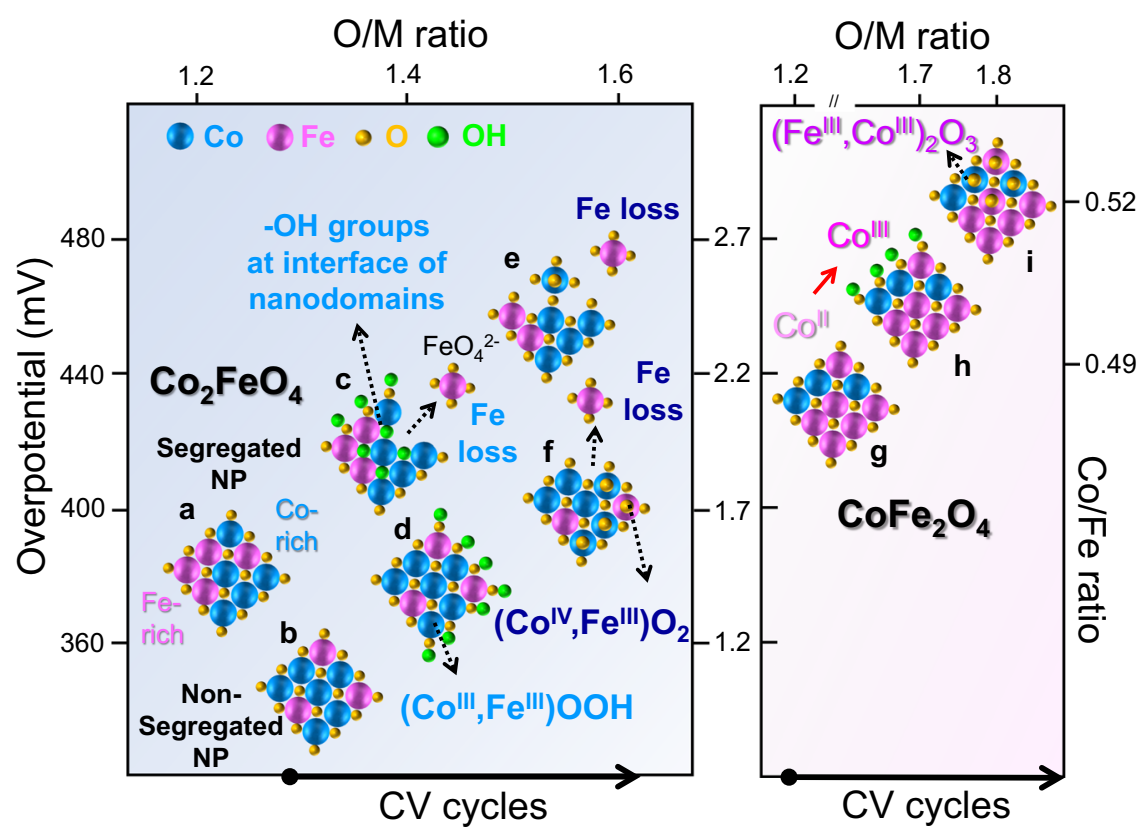

Fig. 8 Schematic diagram of the gradual changes of $\mathrm{Co}_{2} \mathrm{FeO}_{\mathbf{4}}$ and $\mathrm{CoFe}_{\mathbf{2}} \mathrm{O}_{\mathbf{4}}$ with increasing $\mathbf{C V}$ cycles under the OER conditions. The pristine $\mathrm{CO}_{2} \mathrm{FeO}{ }_{4}$ is comprised of a segregated $\mathrm{CO}_{2} \mathrm{FeO}_{4}$ with Fe-rich and $\mathrm{Co}$-rich nanodomains and $\mathbf{b}$ non-segregated $\mathrm{Co}_{2} \mathrm{FeO}_{4}$ nanoparticles. The interface between $\mathrm{Co}$-rich and $\mathrm{Fe}$-rich nanodomains of segregated $\mathrm{CO}_{2} \mathrm{FeO}_{4}$ is thought to provide trapping sites for $\mathbf{c}$ hydroxyl groups, thereby contributing to a lower overpotential of pristine $\mathrm{CO}_{2} \mathrm{FeO}_{4}$ than that of $\mathbf{g}$ pristine $\mathrm{CoFe}_{2} \mathrm{O}_{4}$. At the beginning of electrolysis, concurrent structural transformation to $\mathbf{c}, \mathbf{d} \mathrm{Co}$ IIIOOH and $\mathbf{c}$, e, $\mathbf{f} \mathrm{Fe}$ dissolution occurred for both segregated and non-segregated $\mathrm{Co}_{2} \mathrm{FeO}_{4}$. In addition, $\mathbf{f}$ stable $\left(\mathrm{Co}^{\mathrm{IV}}, \mathrm{Fe}^{\mathrm{III}}\right) \mathrm{O}_{2}$ is formed on the surface of $\mathrm{Co}_{2} \mathrm{FeO}_{4}$, further degrading its activity. The OER activity of $\mathrm{CoFe}_{2} \mathrm{O}_{4}$ also decreases as the number of $\mathrm{CV}$ cycles increases, which is due to $\mathbf{h}$ oxidation of $\mathrm{Co}$ (II) to $\mathrm{Co}$ (III) and i the formation of the stable $\left(\mathrm{Fe}^{I I I}, \mathrm{Co}^{\mathrm{III}}\right)_{2} \mathrm{O}_{3}$ phase on the surface. (The left axis is overpotential at $10 \mu \mathrm{A} / \mathrm{cm}^{2}$, the top axis is the average $\mathrm{O} / \mathrm{M}$ ratio, the right axis is the average $\mathrm{Co} / \mathrm{Fe}$ ratio, and the bottom arrows point to the trend of increasing CV cycles).

driven by spinodal decomposition ${ }^{21,22}$, and 'non-segregated' $\mathrm{Co}_{2} \mathrm{FeO}_{4}$ in pristine $\mathrm{Co}_{2} \mathrm{FeO}_{4}$ (Fig. $8 \mathrm{a}$, b). We speculate that such composition modulation is present in mixed $\mathrm{Co}_{\mathrm{x}} \mathrm{Fe}_{(3-\mathrm{x})} \mathrm{O}_{4}$ spinel oxides when $\mathrm{x}$ is in the range of 1.1-2.7 due to the miscibility gap. The interface between the Co-rich and Fe-rich nanodomains of 'segregated' $\mathrm{Co}_{2} \mathrm{FeO}_{4}$ (Fig. 4j, k) traps the hydroxyl groups, possibly due to the elastic strain induced by the difference in lattice constants (Fig. 8c). At the onset of OER, $\left(\mathrm{Co}^{\mathrm{III}}, \mathrm{Fe}{ }^{\mathrm{III}}\right) \mathrm{OOH}$ is formed epitaxially on the surface of non-segregated $\mathrm{Co}_{2} \mathrm{FeO}_{4}$ (Fig. 3b and Supplementary Fig. 9a, b), and possibly in the nanodomains of segregated $\mathrm{Co}_{2} \mathrm{FeO}_{4}$ nanoparticles (Fig. 8d). Despite the formation of active $\left(\mathrm{Co}^{\mathrm{III}}, \mathrm{Fe}^{\mathrm{III}}\right) \mathrm{OOH}^{13}$, the activity of $\mathrm{Co}_{2} \mathrm{FeO}_{4}$ decreases as a consequence of the irreversible structural transform towards $\left(\mathrm{Co}^{\mathrm{IV}}, \mathrm{Fe}^{\mathrm{III}}\right) \mathrm{O}_{2}$ (Fig. $3 \mathrm{c}$ and Supplementary Fig. 2f) along with gradual loss of Fe (Tables 1 and 2, Figs. $4 \mathrm{~m}, \mathrm{n}$ and $5 \mathrm{~m}, \mathrm{n}$ ) via the formation of soluble ferrate ions $\mathrm{FeO}_{4}{ }^{2-}$ in alkaline electrolytes ${ }^{13,43,56}$ (Fig. 8c, e-f). Therefore, we conclude that the concurrent structural transformation towards a stable $\left(\mathrm{Co}^{\mathrm{IV}}, \mathrm{Fe}^{\mathrm{III}}\right) \mathrm{O}_{2}$ phase and $\mathrm{Fe}$ dissolution lead to a decrease in OER activity of $\mathrm{Co}_{2} \mathrm{FeO}_{4}$ as the number of $\mathrm{CV}$ cycles increases. For $\mathrm{CoFe}_{2} \mathrm{O}_{4}, \mathrm{Co}^{\mathrm{II}}$ present on the surface of pristine sample (Fig. 8g) is oxidised to $\mathrm{Co}^{\mathrm{III}}$ at the onset of OER (Fig. 8h), as shown by XPS data (Fig. 2b). After 1000 cycles, the (Fe ${ }^{\mathrm{III}}$, $\left.\mathrm{Co}^{\mathrm{III}}\right)_{2} \mathrm{O}_{3}$ phase, whose dimension is $4-5 \mathrm{~nm}$, is likely formed on the surface of $\mathrm{CoFe}_{2} \mathrm{O}_{4}$ (Fig. 8i), as evidenced by both HRTEM and electron diffraction pattern (Fig. $3 \mathrm{f}$ and Supplementary Fig. 3f) and oxygen-rich regions revealed by APT (Fig. 6k, l, n), which slightly decreased the OER activity.

Importantly, our study demonstrates that OER is catalysed concurrently by multiple active regions in a single nanoparticle. Firstly, we observe that $\mathrm{Co}^{\mathrm{II}}$ catalyses the OER of both $\mathrm{Co}_{2} \mathrm{FeO}_{4}$ and $\mathrm{CoFe}_{2} \mathrm{O}_{4}$, since the $\mathrm{Co}$ oxidation state increases (indicated by XPS in Fig. 2 and XANES in Supplementary Fig. 7). The $\mathrm{Co}^{\mathrm{II}}$ in the tetragonal sites (termed $C o_{T d}^{I I}$ ) are thought to be active sites as they are responsible for the formation of active $\mathrm{Co}^{\mathrm{III}} \mathrm{OOH}$ species ${ }^{17}$; this is confirmed by our TEM data (Fig. 3b and Supplementary Fig. 9a, b) and the decreased number of tetrahedral sites by XANES data (inset, Supplementary Fig. 7a) as well as EIS data (Fig. 7a) after OER. Secondly, and most importantly, our results demonstrate that, $\mathrm{Fe}$, when in the presence of $C o_{T d}^{I I}$, plays a key role in the OER activity. Specifically, the amount of Fe loss is thought to indicate how rigorously OER occurs. Our APT data (Table 1) reveals that different regions have various levels of $\mathrm{Fe}$ dissolution, i.e., oxygen-rich regions of $\mathrm{CoFe}_{2} \mathrm{O}_{4}<$ oxygen-rich regions of non-segregated $\mathrm{Co}_{2} \mathrm{FeO}_{4} \leq \mathrm{Fe}$ rich nanodomains in segregated $\mathrm{Co}_{2} \mathrm{FeO}_{4}<\mathrm{Co}$-rich nanodomains in segregated $\mathrm{Co}_{2} \mathrm{FeO}_{4}$. The number of $\mathrm{Co}_{T d}^{I I}$ sites in these regions also increases in a similar manner (as indicated by Supplementary Table 3, estimated according to refs. ${ }^{57,58}$ ). These observations provide a strong indication that $\mathrm{Fe}$, which can actively catalyse $\mathrm{OER}$, seems to be associated with the number of $C o_{T d}^{I I}$ sites. Therefore, we hypothesis that the presence of Co oxyhydroxide is imperative for the activation of $\mathrm{Fe}$, since $\mathrm{FeOOH}$ has low electrical conductivity and stability at lower potentials ${ }^{56}$, and $\mathrm{Co}^{\mathrm{III}} \mathrm{OOH}$ provides an electrically conductive support ${ }^{9}$. A previous study reported that $\mathrm{Fe}$ can serve as an indirect active site, for example by changing the spin and charge state of $\mathrm{Co}^{11}$, or by assisting ${ }^{5}$ or stabilising the active $\mathrm{Co}^{\mathrm{III}} \mathrm{OOH}$ intermediate ${ }^{59}$, thereby enhancing OER activity. Another study proposed that di- $\mu$-oxo bridged Co-Fe sites act as active sites above a transition voltage, below which di- $\mu$-oxo bridged Co-Co sites catalyse $\mathrm{OER}^{4}$. Our study indicates that Fe promotes the formation of active species for OER, possibly $\mathrm{Co}^{\mathrm{III}} \mathrm{Fe} \mathrm{III}^{\mathrm{IIOOH}}$, whose OER activity is significantly better than that of $\mathrm{Co}^{\mathrm{III}} \mathrm{OOH}^{13}$ (although its activity drops rapidly due to Fe dissolution). Therefore, in comparison to $\mathrm{CoFe}_{2} \mathrm{O}_{4}, \mathrm{Co}_{2} \mathrm{FeO}_{4}$ has a higher OER activity most likely due to the formation of more $\mathrm{Co}^{\mathrm{III}} \mathrm{Fe} \mathrm{FII}^{\mathrm{III}} \mathrm{OH}$ yielded by its optimal ratio of Fe content to $\mathrm{Co}_{T d}^{I I}$ sites. Also, the interface between 
the nanodomains of segregated $\mathrm{Co}_{2} \mathrm{FeO}_{4}$ traps hydroxyl groups, providing additional active regions for OER, thereby further enhancing the OER activity of $\mathrm{Co}_{2} \mathrm{FeO}_{4}$. Therefore, we conclude that the presence of $\mathrm{Co}^{\mathrm{III}} \mathrm{Fe}^{\mathrm{III}} \mathrm{OOH}$, promoted by $\mathrm{Fe}$ and $\mathrm{Co}_{T d}^{I I}$, coupled with the nanosized defect features, leads to $\mathrm{Co}_{2} \mathrm{FeO}_{4}$ having an increased OER activity. This potentially explains how the addition of a small amount of $\mathrm{Fe}$ improves the OER activity of mixed Co-Fe spinel oxides 7,8 .

In summary, our study provides atomic-scale insights into the evolving surface structure of $\mathrm{Co}_{2} \mathrm{FeO}_{4}$ and $\mathrm{CoFe}_{2} \mathrm{O}_{4}$ nanoparticles during OER and reveals how those structural and compositional changes alter the activity and stability. We demonstrate the importance of 3D atomic-scale imaging and quantitative compositional analysis of nanoparticles in both their pristine state and at various stages of electrochemical reaction when seeking to understand their activity and stability. We believe that APT, when combined with X-ray- and electron-based characterisation techniques, has enormous potential to better understand the reaction and degradation mechanisms of oxide or metallic catalyst nanoparticles during important reactions, such as OER and $\mathrm{CO}_{2}$ reduction.

\section{Methods}

Synthesis of nanoparticles. Iron (III) nitrate $\left(\mathrm{Fe}\left(\mathrm{NO}_{3}\right)_{3} \cdot 9 \mathrm{H}_{2} \mathrm{O}\right)$, cobalt (II) nitrate $\left(\mathrm{Co}\left(\mathrm{NO}_{3}\right)_{2} \cdot 6 \mathrm{H}_{2} \mathrm{O}\right)$, ammonia $\left(\mathrm{NH}_{3} \cdot \mathrm{H}_{2} \mathrm{O}\right)$ and polyethene glycol $(\mathrm{PEG}, \mathrm{Mn}=400)$ were purchased from Sinopharm Chemical Reagent (Shanghai, China). The $\mathrm{CoFe}_{2} \mathrm{O}_{4}$ nanoparticles were prepared by dissolving $3.2 \mathrm{~g}$ of $\mathrm{Fe}\left(\mathrm{NO}_{3}\right)_{3} \cdot 9 \mathrm{H}_{2} \mathrm{O}, 1.2 \mathrm{~g}$ of $\mathrm{Co}\left(\mathrm{NO}_{3}\right)_{2} \cdot 6 \mathrm{H}_{2} \mathrm{O}$ and $0.2 \mathrm{~g}$ of polyethene glycol (PEG, $\left.\mathrm{Mn}=400\right)$ in $40 \mathrm{~mL}$ of ultrapure water $\left(0.055 \mu \mathrm{S} \mathrm{cm}{ }^{-1}\right)$ under vigorous stirring for $30 \mathrm{~min}^{60}$. For $\mathrm{Co}_{2} \mathrm{FeO}_{4}$ nanoparticles, $1.6 \mathrm{~g}$ of $\mathrm{Fe}\left(\mathrm{NO}_{3}\right)_{3} \cdot 9 \mathrm{H}_{2} \mathrm{O}, 2.3 \mathrm{~g}$ of $\mathrm{Co}\left(\mathrm{NO}_{3}\right)_{2} \cdot 6 \mathrm{H}_{2} \mathrm{O}$ and $0.2 \mathrm{~g}$ of PEG were mixed in $40 \mathrm{~mL}$ of ultrapure water. $5 \mathrm{~mL}$ of ammonia diluted with $5 \mathrm{~mL}$ of ultrapure water was slowly added dropwise into the solution mixture. The obtained suspension was subsequently transferred into a $100 \mathrm{~mL}$ Teflon-lined stainless autoclave, maintained at $180^{\circ} \mathrm{C}$ for $3 \mathrm{~h}$. The product was washed several times with ultrapure water via centrifugation, dried in an oven at $80^{\circ} \mathrm{C}$ for $12 \mathrm{~h}$.

XRD measurements. The XRD analysis of the pristine $\mathrm{Co}_{2} \mathrm{FeO}_{4}$ and $\mathrm{CoFe}_{2} \mathrm{O}_{4}$ nanoparticles was performed on an Rigaku Ultima IV diffractometer with $\mathrm{Cu} \mathrm{Ka}$ radiation $(\lambda=0.15418 \mathrm{~nm})$ at a scanning speed of $4^{\circ} / \mathrm{min}$, scanning step of $0.02^{\circ}$ and operating voltage of $40 \mathrm{kV}$. The XRD data was given in Supplementary Fig. 1 .

TEM measurements. TEM and HRTEM experiments were carried out in an aberration-corrected JEOL JEM-2200FS operating at $200 \mathrm{kV}$, and TEM/EDX data was acquired with an Oxford X-max detector. The TEM samples were prepared by dispersing a small amount of nanoparticles into anhydrous ethanol via ultrasonication, followed by dropping nanoparticle solutions on $\mathrm{Cu}$ TEM grids and dried at room temperature. The HRTEM images were processed by using Gatan Digital Micrograph. Additional TEM images were shown in Supplementary Figs. 2, 3, and 8-10.

Electrochemical measurements. Electrochemical measurements were performed in a three-electrode system at an electrochemical workstation (PalmSens3), where a Pt wire and $\mathrm{Ag} / \mathrm{AgCl}(3 \mathrm{M} \mathrm{KCl})$ served as counter and reference electrodes. The OER performance was studied by using a rotating disk electrode $(10 \mathrm{~mm}$ diameter, $0.785 \mathrm{~cm}^{2}$ ). The glassy carbon electrode was first cleaned and polished to a mirror finish with $50 \mathrm{~nm} \mathrm{Al}_{2} \mathrm{O}_{3}$. In all, $32 \mu \mathrm{L}$ of dispersion was transferred onto the glassy carbon disk and then dried at room temperature. The dispersion was prepared by dispersing $5 \mathrm{mg}$ of nanoparticle powder in $1 \mathrm{~mL}$ ultrapure water, followed by ultrasonication for $30 \mathrm{~min}$. The LSV curves were recorded with a scan rate of $10 \mathrm{mV} / \mathrm{s}$ in $1.0 \mathrm{M} \mathrm{KOH}$ solution from $0 \mathrm{~V}$ to $0.8 \mathrm{~V}$ (vs $\mathrm{Ag} / \mathrm{AgCl}$ ) at a rotating speed of $1600 \mathrm{rpm}$. The CV measurements were performed at a scan rate of $50 \mathrm{mV} / \mathrm{s}$ from $0 \mathrm{~V}$ to $0.65 \mathrm{~V}$ (vs $\mathrm{Ag} / \mathrm{AgCl}$ ). Electrochemical data normalised to electrode geometric surface area was provided in Supplementary Fig. 5. Another set of electrochemical measurements was carried out at the same conditions except for the KOD solution in $\mathrm{D}_{2} \mathrm{O}$ for APT specimen preparation and measurements. The deuterium oxide $\left(\mathrm{D}_{2} \mathrm{O}\right.$ with 99.9 at.\% $\left.\mathrm{D}\right)$ and potassium deuteroxide solution (40 wt.\% KOD in $\mathrm{D}_{2} \mathrm{O}$ with 98 at.\% D) were purchased from Sigma-Aldrich. EIS was performed under OER conditions by applying a sine wave signal with a $10 \mathrm{mV}$ amplitude in the frequency range from $6 \mathrm{kHz}$ to $0.2 \mathrm{~Hz}$ after equilibrating $5 \mathrm{~s}$ at $0.6 \mathrm{~V}$ vs. $\mathrm{Ag} / \mathrm{AgCl}$ for $\mathrm{Co}_{2} \mathrm{FeO}_{4}$ and $0.7 \mathrm{~V}$ vs. $\mathrm{Ag} / \mathrm{AgCl}$ for $\mathrm{CoFe}_{2} \mathrm{O}_{4}$. The software RelaxIS 3 (rhd instruments) was used for data treatment and analysis (details were given in Supplementary Note 4, Supplementary Figs. 24 and 25).

$\mathbf{N}_{2}$ Physisorption measurements. The $\mathrm{N}_{2}$ sorption experiments were carried out in a physical adsorption analyser (TriStar II 3020, Micromeritics). In all, $87 \mathrm{mg}$ $\mathrm{CoFe}_{2} \mathrm{O}_{4}$ and $72 \mathrm{mg} \mathrm{Co}_{2} \mathrm{FeO}_{4}$ nanoparticles were degassed at $150{ }^{\circ} \mathrm{C}$ for $8 \mathrm{~h}$ under vacuum before measurement. The BET surface area was calculated within the relative pressure range of $0.05-0.3\left(p / p^{\circ}\right)$. Data was shown in Supplementary Fig. 4.

XPS measurements. XPS measurements were performed on a VersaProbe II (Ulvac-Phi) using a monochromatic Al X-ray source $(1486.6 \mathrm{eV})$ operating at $15 \mathrm{kV}$ and $13.2 \mathrm{~W}$. The emission angle between the analyser and the substrate surface is $45^{\circ}$. The binding energy scale was referenced to the main $\mathrm{C} 1 \mathrm{~s}$ signal at $284.8 \mathrm{eV}$. Detailed Analysis of the spectra was carried out with the software CasaXPS. Peak fitting was revealed in Supplementary Fig. 6.

XAS measurements. Co K $\beta$ High Energy Resolution Fluorescence Detected (HERFD) XAS and Co K $\beta$ XES were collected at beamline I20 at the Diamond Light Source ( $3 \mathrm{GeV}, 300 \mathrm{~mA})$. A Si (111) double crystal monochromator was used for energy selection of the incident beam, and a rhodium-coated mirror was used for harmonic rejection, delivering a flux of $\sim 4 \times 10^{12}$ photons/s at the sample position. X-rays were focused to achieve an approximate beam size of $100 \times 300 \mu \mathrm{m}^{2}(\mathrm{VxH})$. A Johann-type XES spectrometer was used with two Ge (444) crystals aligned by setting the maximum of the $\mathrm{K} \beta$ emission line of a Co foil to $7059.1 \mathrm{eV}$. The incident energy was calibrated by setting the first inflection point of the Co XAS spectra to $7709.0 \mathrm{eV}$ for a Co foil. Co K $\beta$ XES spectra were collected from 7620 to $7670 \mathrm{eV}$, with a step size of $0.2 \mathrm{eV}$. The HERFD XAS edge spectra were collected with the spectrometer fixed at the maximum of the $\mathrm{K} \beta$ emission energy while scanning the energy of the incident monochromator. Co K $\beta$-detected HERFD XAS spectra were collected from 7690 to $7745 \mathrm{eV}$, with a step size of $0.25 \mathrm{eV}$ over the edge region $(7690-7725 \mathrm{eV})$ and steps of $0.5 \mathrm{eV}$ over the EXAFS region $(7725-8500 \mathrm{eV})$. Co and Fe K-edge XAS spectra were collected in fluorescence mode using a 4-element Vortex Si-drift detector for all samples but the Co $\mathrm{Kb}$ detected HERFD for $\mathrm{CoFe}_{2} \mathrm{O}_{4}$. Pre-edge baseline corrections were done using Larch XAS Viewer ${ }^{61}$. XAS data are discussed in Supplementary Note 1 and shown in Supplementary Fig. 7.

APT measurements. Before preparing the needle-shaped APT specimen, a bulk material containing nanoparticles was fabricated by the following procedure. A nanoparticle suspension was prepared by mixing $5.0 \mathrm{mg}$ of nanoparticles in $1.0 \mathrm{ml}$ of $\mathrm{D}_{2} \mathrm{O}$ water, followed by ultrasonication for $30 \mathrm{~min}$. $20 \mu \mathrm{L}$ of nanoparticle solutions were dropped on a clean glassy carbon and dried at room temperature overnight. The CV measurements were performed on the glassy carbon electrodes in $1 \mathrm{M} \mathrm{KOD} \mathrm{(in} \mathrm{D}_{2} \mathrm{O}$ ) solution at a scan rate of $50 \mathrm{mV} / \mathrm{s}$ from $0 \mathrm{~V}$ to $0.65 \mathrm{~V}$ (vs Ag/ $\mathrm{AgCl}$ ) for 100,500 and 1000 cycles, respectively. Afterwards, the glassy carbon electrode was covered by $\mathrm{Ni}$ electrodeposition at a constant voltage of $-1.5 \mathrm{~V}$ for $300 \mathrm{~s}$ in an electrolyte mixed with $3.0 \mathrm{~g}$ nickel sulphate, $0.5 \mathrm{~g}$ nickel chloride, and $0.5 \mathrm{~g}$ boric acid in $10 \mathrm{ml}$ DI water ${ }^{62}$. This bulk material was subsequently used to prepare needle-shaped APT specimens by a lift-out procedure using a focus ion beam/scanning electron microscope (FEI Helios G4 CX) (details are shown in Supplementary Note 2 and Supplementary Fig. 11). The APT experiments were conducted in CAMECA LEAP 5000XR instrument in laser pulsing mode at a specimen temperature of $57 \mathrm{~K}$, laser energy of $30 \mathrm{pJ}$, pulse frequency of $125 \mathrm{kHz}$, and detection rates of 0.5 . The APT data are reconstructed and analysed using the commercial IVAS 3.8.2 software. Additional APT data and analysis were listed in Supplementary Figs. 12-22 and Supplementary Note 3.

$\mathbf{H}_{\mathbf{2}}$ TPR measurements. The $\mathrm{H}_{2}$ TPR measurements were conducted in a flow setup consisting of a gas supply, a stainless-steel U-tube reactor heated in a ceramic tube furnace, and a thermal conductivity detector (TCD, Hydros 100). For the measurement, $116.6 \mathrm{mg}$ catalyst nanoparticles were pre-treated in $50 \mathrm{Nml} \mathrm{\textrm {min } ^ { - 1 }}$ $\mathrm{He}(99.9999 \%)$ at $400{ }^{\circ} \mathrm{C}$ for $1 \mathrm{~h}$. After cooling to $60^{\circ} \mathrm{C}$, the set-up was flushed with $50 \mathrm{Nml} \mathrm{min}{ }^{-1} 4.58 \% \mathrm{H}_{2}$ (99.9999\%)/Ar (99.9995\%) for $1 \mathrm{~h}$. The furnace was heated to $800{ }^{\circ} \mathrm{C}$ with a heating rate of $10 \mathrm{~K} \mathrm{~min}^{-1}$. The maximum temperature was kept constant for $1 \mathrm{~h}$. The temperature of the sample was measured every two seconds by a thermocouple placed inside the reactor. The arising water was condensed in a cold trap. The measured consumption of $\mathrm{H}_{2}$ and temperature were plotted against the measurement time. Experimental data was shown in Supplementary Fig. 23 and Supplementary Note 3.

\section{Data availability}

The raw datasets generated and/or analysed during the current study are available in Figshare $^{63}$. Source data are provided with this paper.

Received: 24 August 2021; Accepted: 8 December 2021; Published online: 10 January 2022

\section{References}

1. Grimaud, A. et al. Activation of surface oxygen sites on an iridium-based model catalyst for the oxygen evolution reaction. Nat. Energy 2, 16189 (2016). 
2. Grimaud, A. et al. Activating lattice oxygen redox reactions in metal oxides to catalyse oxygen evolution. Nat. Chem. 9, 457-465 (2017).

3. $\mathrm{Li}, \mathrm{M}$. et al. Facile synthesis of electrospun $\mathrm{MFe} 2 \mathrm{O} 4(\mathrm{M}=\mathrm{Co}, \mathrm{Ni}, \mathrm{Cu}, \mathrm{Mn})$ spinel nanofibers with excellent electrocatalytic properties for oxygen evolution and hydrogen peroxide reduction. Nanoscale 7, 8920-8930 (2015).

4. Smith, R. D. L. et al. Spectroscopic identification of active sites for the oxygen evolution reaction on iron-cobalt oxides. Nat. Commun. 8, 2022 (2017).

5. $\mathrm{Wu}, \mathrm{T}$. et al. Iron-facilitated dynamic active-site generation on spinel $\mathrm{CoAl} 2 \mathrm{O} 4$ with self-termination of surface reconstruction for water oxidation. Nat. Catal. 2, 763-772 (2019).

6. Sickafus, K. E., Wills, J. M. \& Grimes, N. W. Structure of spinel. J. Am. Ceram. Soc. 82, 3279-3292 (1999).

7. Budiyanto, E. et al. Tailoring morphology and electronic structure of cobalt iron oxide nanowires for electrochemical oxygen evolution reaction. ACS Appl. Energy Mater. 3, 8583-8594 (2020).

8. Hung, S. F. et al. Unraveling geometrical site confinement in highly efficient iron-doped electrocatalysts toward oxygen evolution reaction. Adv. Energy Mater. 8, 1701686 (2018).

9. Burke, M. S., Kast, M. G., Trotochaud, L., Smith, A. M. \& Boettcher, S. W. Cobalt-iron (oxy) hydroxide oxygen evolution electrocatalysts: the role of structure and composition on activity, stability, and mechanism. J. Am. Chem. Soc. 137, 3638-3648 (2015).

10. Enman, L. J. et al. Operando X-ray absorption spectroscopy shows iron oxidation is concurrent with oxygen evolution in cobalt-iron (oxy) hydroxide electrocatalysts. Angew. Chem. Int. Ed. 57, 12840-12844 (2018).

11. Wang, X. T. et al. Redox-inert Fe3+ ions in octahedral sites of Co-Fe spinel oxides with enhanced oxygen catalytic activity for rechargeable zinc-air batteries. Angew. Chem. 131, 13425-13430 (2019).

12. Feng, C. et al. Fe-based electrocatalysts for oxygen evolution reaction: progress and perspectives. ACS Catal. 10, 4019-4047 (2020).

13. Chung, D. Y. et al. Dynamic stability of active sites in hydr(oxy)oxides for the oxygen evolution reaction. Nat. Energy 5, 222-230 (2020).

14. El Arrassi, A. et al. Intrinsic activity of oxygen evolution catalysts probed at single $\mathrm{CoFe}_{2} \mathrm{O}_{4}$ nanoparticles. J. Am. Chem. Soc. 141, 9197-9201 (2019).

15. Zhang, M., De Respinis, M. \& Frei, H. Time-resolved observations of water oxidation intermediates on a cobalt oxide nanoparticle catalyst. Nat. Chem. 6, 362-367 (2014).

16. Bergmann, A. et al. Reversible amorphization and the catalytically active state of crystalline $\mathrm{Co}_{3} \mathrm{O}_{4}$ during oxygen evolution. Nat. Commun. 6, 8625 (2015).

17. Wang, H. Y. et al. In operando identification of geometrical-site-dependent water oxidation activity of spinel $\mathrm{Co}_{3} \mathrm{O}_{4}$. J. Am. Chem. Soc. 138, 36-39 (2016)

18. Wang, H. Y. et al. In situ spectroscopic identification of mu-OO bridging on spinel $\mathrm{Co}_{3} \mathrm{O}_{4}$ water oxidation electrocatalyst. J. Phys. Chem. Lett. 7, 4847-4853 (2016).

19. Hsu, C. S. et al. Valence- and element-dependent water oxidation behaviors: in situ X-ray diffraction, absorption and electrochemical impedance spectroscopies. Phys. Chem. Chem. Phys. 19, 8681-8693 (2017)

20. Calvillo, L. et al. Insights into the durability of Co-Fe spinel oxygen evolution electrocatalysts via operando studies of the catalyst structure. J. Mater. Chem. A 6, 7034-7041 (2018).

21. Takahashi, M., Guimaraes, J. \& Fine, M. Spinodal decomposition in the system $\mathrm{CoFe}_{2} \mathrm{O}_{4}-\mathrm{Co}_{3} \mathrm{O}_{4}$. J. Am. Ceram. Soc. 54, 291-295 (1971).

22. Dinh, T. M. C. et al. FIB plan view lift-out sample preparation for TEM characterization of periodic nanostructures obtained by spinodal decomposition in $\mathrm{Co} 1.7 \mathrm{Fe} 1.3 \mathrm{O}_{4}$ thin films. Cryst. Eng. Comm. 20, 6146-6155 (2018).

23. Smith, W. \& Hobson, A. The structure of cobalt oxide, $\mathrm{Co}_{3} \mathrm{O}_{4}$. Acta Crystallogr. Sect. B 29, 362-363 (1973).

24. $\mathrm{Wu}, \mathrm{G}$. et al. A strategy to promote the electrocatalytic activity of spinels for oxygen reduction by structure reversal. Angew. Chem. Int. Ed. 55, 1340-1344 (2016).

25. Hamdani, M., Singh, R. \& Chartier, P. $\mathrm{Co}_{3} \mathrm{O}_{4}$ and $\mathrm{Co}-$ based spinel oxides bifunctional oxygen electrodes. Int. J. Electrochem. Sci. 5, 556-577 (2010).

26. Palmas, S., Ferrara, F., Vacca, A., Mascia, M. \& Polcaro, A. Behavior of cobalt oxide electrodes during oxidative processes in alkaline medium. Electrochim. Acta 53, 400-406 (2007).

27. Bergmann, A. et al. Unified structural motifs of the catalytically active state of Co (oxyhydr) oxides during the electrochemical oxygen evolution reaction. Nat. Catal. 1, 711-719 (2018).

28. Alex, C., Sarma, S. C., Peter, S. C. \& John, N. S. Competing effect of $\mathrm{Co}^{3+}$ reducibility and oxygen-deficient defects toward high oxygen evolution activity in $\mathrm{Co}_{3} \mathrm{O}_{4}$ systems in alkaline medium. ACS Appl. Energy Mater. 3, 5439-5447 (2020).

29. Nkeng, P. et al. Characterization of spinel-type cobalt and nickel oxide thin films by X-ray near grazing diffraction, transmission and reflectance spectroscopies, and cyclic voltammetry. J. Electrochem. Soc. 142, 1777 (1995).
30. Shinagawa, T., Garcia-Esparza, A. T. \& Takanabe, K. Insight on Tafel slopes from a microkinetic analysis of aqueous electrocatalysis for energy conversion. Sci. Rep. 5, 13801 (2015).

31. Oku, M. \& Hirokawa, K. X-ray photoelectron spectroscopy of Co3O4, Fe3O4 $\mathrm{Mn3 \textrm {O }}$, and related compounds. J. Electron Spectrosc. Relat. Phenomena 8, 475-481 (1976).

32. Liu, B., Zhang, Y. \& Tang, L. X-ray photoelectron spectroscopic studies of $\mathrm{Ba} 0$ 5Sr0. 5Co0. $8 \mathrm{Fe} 0.2 \mathrm{O} 3-\delta$ cathode for solid oxide fuel cells. Int. J. Hydrog. Energy 34, 435-439 (2009).

33. Madhu, R. et al. Honeycomb-like porous carbon-cobalt oxide nanocomposite for high-performance enzymeless glucose sensor and supercapacitor applications. ACS Appl. Mater. Interfaces 7, 15812-15820 (2015).

34. Menezes, P. W. et al. Uncovering the prominent role of metal ions in octahedral versus tetrahedral sites of cobalt-zinc oxide catalysts for efficient oxidation of water. J. Mater. Chem. A 4, 10014-10022 (2016).

35. Biesinger, M. C. et al. Resolving surface chemical states in XPS analysis of first row transition metals, oxides and hydroxides: $\mathrm{Cr}, \mathrm{Mn}, \mathrm{Fe}, \mathrm{Co}$ and Ni. Appl. Surf. Sci. 257, 2717-2730 (2011).

36. Dahéron, L. et al. Electron transfer mechanisms upon lithium deintercalation from $\mathrm{LiCoO}_{2}$ to $\mathrm{CoO}_{2}$ investigated by XPS. Chem. Mater. 20, 583-590 (2008)

37. De Groot, F., Vankó, G. \& Glatzel, P. The 1s X-ray absorption pre-edge structures in transition metal oxides. J. Phys. Condens. Matter 21, 104207 (2009).

38. Delaplane, R. G., Ibers, J. A., Ferraro, J. R. \& Rush, J. J. Diffraction and spectroscopic studies of the cobaltic acid system $\mathrm{HCoC}_{2}-\mathrm{DCoO}_{2}$. J. Chem. Phys. 50, 1920-1927 (1969).

39. Amatucci, G., Tarascon, J. \& Klein, L. $\mathrm{CoO}_{2}$, the end member of the $\mathrm{Li} \mathrm{x}$ $\mathrm{CoO}_{2}$ solid solution. J. Electrochem. Soc. 143, 1114 (1996).

40. Bajdich, M., García-Mota, M., Vojvodic, A., Nørskov, J. K. \& Bell, A. T. Theoretical investigation of the activity of cobalt oxides for the electrochemical oxidation of water. J. Am. Chem. Soc. 135, 13521-13530 (2013).

41. Post, J. E. \& Buchwald, V. F. Crystal structure refinement of akaganeite. Am. Mineral. 76, 272-277 (1991).

42. Finger, L. W. \& Hazen, R. M. Crystal structure and isothermal compression of $\mathrm{Fe}_{2} \mathrm{O}_{3}, \mathrm{Cr}_{2} \mathrm{O}_{3}$, and $\mathrm{V}_{2} \mathrm{O}_{3}$ to 50 kbars. J. Appl. Phys. 51, 5362-5367 (1980).

43. Beverskog, B. \& Puigdomenech, I. Revised pourbaix diagrams for iron at 25-300 C. Corros. Sci. 38, 2121-2135 (1996).

44. Gault, B., Moody, M. P., Cairney, J. M. \& Ringer, S. P., Atom Probe Microscopy. Vol. 160 (Springer Science \& Business Media, 2012).

45. Li, T. et al. Atomic imaging of carbon-supported Pt, Pt/Co, and Ir@ Pt nanocatalysts by atom-probe tomography. ACS Catal. 4, 695-702 (2014).

46. Ji, Z., Li, T. \& Yaghi, O. M. Sequencing of metals in multivariate metal-organic frameworks. Science 369, 674-680 (2020).

47. $\mathrm{Li}, \mathrm{T}$. et al. Atomic-scale insights into surface species of electrocatalysts in three dimensions. Nat. Catal. 1, 300-305 (2018).

48. Devaraj, A., Colby, R., Hess, W. P., Perea, D. E. \& Thevuthasan, S. Role of photoexcitation and field ionization in the measurement of accurate oxide stoichiometry by laser-assisted atom probe tomography. J. Phys. Chem. Lett. 4 , 993-998 (2013)

49. Kasian, O. et al. Degradation of iridium oxides via oxygen evolution from the lattice: correlating atomic scale structure with reaction mechanisms. Energy Environ. Sci. 12, 3548-3555 (2019).

50. Schiller, C., Richter, F., Gülzow, E. \& Wagner, N. Validation and evaluation of electrochemical impedance spectra of systems with states that change with time. Phys. Chem. Chem. Phys. 3, 374-378 (2001).

51. Wan, T. H., Saccoccio, M., Chen, C. \& Ciucci, F. Influence of the discretization methods on the distribution of relaxation times deconvolution: implementing radial basis functions with DRTtools. Electrochim. Acta 184, 483-499 (2015).

52. Conway, B. \& Liu, T. Behaviour of surface intermediate states in anodic $\mathrm{O} 2$ evolution electrocatalysis at $\mathrm{Co}_{3} \mathrm{O}_{4}$ on $\mathrm{Ni}$ and $\mathrm{Ti}$ substrates. Ber. Bunsenges. Phys. Chem. 91, 461-469 (1987).

53. Dionigi, F. et al. Intrinsic electrocatalytic activity for oxygen evolution of crystalline 3d-transition metal layered double hydroxides. Angew. Chem. Int. Ed. Engl. 60, 14446-14457 (2021).

54. Liu, T.-C., Pell, W. \& Conway, B. Stages in the development of thick cobalt oxide films exhibiting reversible redox behavior and pseudocapacitance. Electrochim. Acta 44, 2829-2842 (1999).

55. Linnemann, J., Kanokkanchana, K. \& Tschulik, K. Design strategies for electrocatalysts from an electrochemist's perspective. ACS Catal. 11, 5318-5346 (2021)

56. Burke, M. S. et al. Revised oxygen evolution reaction activity trends for firstrow transition-metal (oxy) hydroxides in alkaline media. J. Phys. Chem. Lett. 6, 3737-3742 (2015).

57. Carraro, F. et al. In operando XAS investigation of reduction and oxidation processes in cobalt and iron mixed spinels during the chemical loop reforming of ethanol. J. Mater. Chem. A 5, 20808-20817 (2017). 
58. Jung, I.-H., Decterov, S. A., Pelton, A. D., Kim, H.-M. \& Kang, Y.-B. Thermodynamic evaluation and modeling of the $\mathrm{Fe}-\mathrm{Co}-\mathrm{O}$ system. Acta Mater. 52, 507-519 (2004).

59. Hung, S.-F. et al. Identification of stabilizing high-valent active sites by operando high-energy resolution fluorescence-detected X-ray absorption spectroscopy for high-efficiency water oxidation. J. Am. Chem. Soc. 140, 17263-17270 (2018).

60. Chen, Z. \& Gao, L. Synthesis and magnetic properties of $\mathrm{CoFe}_{2} \mathrm{O}_{4}$ nanoparticles by using PEG as surfactant additive. Mater. Sci. Eng. B 141, 82-86 (2007).

61. Newville, M. Larch: an analysis package for XAFS and related spectroscopies. in Journal of Physics: Conference Series (IOP Publishing, 2013).

62. Kim, S.-H. et al. A new method for mapping the three-dimensional atomic distribution within nanoparticles by atom probe tomography (APT). Ultramicroscopy 190, 30-38 (2018).

63. Xiang, W. et al. Raw data. Figshare. https://doi.org/10.6084/ m9.figshare.17142935.v2 (2021).

\section{Acknowledgements}

W.X. and T.L. thank Deutsche Forschungsgemeinsschaft (DFG) for financial support (project number 407513992). T.F., M.M., J.L., K.T., O.R., S.D., T.L., U.H. and M.H. thank DFG (Projektnummer 388390466 - TRR 247/ A1, A2, B6, C4 and S projects) for financial support. W.X. and T.L. would like to thank Zentrum für grenzflächendominierte Höchstleistungswerkstoffe (ZGH) at Ruhr University Bochum for the access to infrastructure (FEI Helios G4 CX SEM/FIB and Cameca LEAP 5000 XR). O.R. and S.D. thank the Max Planck Society for support. J.L. and K.T. acknowledge the Center for Solvation Science (ZEMOS). T.L. thanks Mr. Arjun BalaKrishnan and Mr. Naiyu Qi for assistance with processing figures.

\section{Author contributions}

T.L. designed, supervised and coordinated the project. N.Y. and X.L. synthesised the nanoparticles and conducted the XRD and BET measurements. W.X. performed the electrochemical measurements, J.L. and K.T. contributed to data analysis and interpretation. U.H. performed the XPS measurements and analysed the XPS data. O.R., M.A. and S.D. performed XAS measurements and data analysis. M.H. performed the TEM measurements and T.L. analysed the TEM data. T.F. and M.M. performed the $\mathrm{H}_{2} / \mathrm{TPR}$ experiment. W.X. performed the APT experiments, W.X. and T.L. analysed the APT data. All authors agreed on the contents and conclusion of the paper.

\section{Funding}

Open Access funding enabled and organized by Projekt DEAL.

\section{Competing interests}

The authors declare no competing interests.

\section{Additional information}

Supplementary information The online version contains supplementary material available at https://doi.org/10.1038/s41467-021-27788-2.

Correspondence and requests for materials should be addressed to Tong Li.

Peer review information Nature Communications thanks Douglas Kauffman, Daniel Perea and the other, anonymous, reviewer(s) for their contribution to the peer review of this work. Peer reviewer reports are available.

Reprints and permission information is available at http://www.nature.com/reprints

Publisher's note Springer Nature remains neutral with regard to jurisdictional claims in published maps and institutional affiliations.

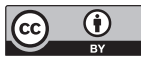

Open Access This article is licensed under a Creative Commons Attribution 4.0 International License, which permits use, sharing, adaptation, distribution and reproduction in any medium or format, as long as you give appropriate credit to the original author(s) and the source, provide a link to the Creative Commons license, and indicate if changes were made. The images or other third party material in this article are included in the article's Creative Commons license, unless indicated otherwise in a credit line to the material. If material is not included in the article's Creative Commons license and your intended use is not permitted by statutory regulation or exceeds the permitted use, you will need to obtain permission directly from the copyright holder. To view a copy of this license, visit http://creativecommons.org/ licenses/by/4.0/.

(C) The Author(s) 2022 